\title{
Physics faculty beliefs and values about the teaching and learning of problem solving. I. Mapping the common core
}

\author{
E. Yerushalmi* \\ Weizmann Institute of Science, Rehovot, Israel, 76100 \\ C. Henderson* \\ Department of Physics, Western Michigan University, Kalamazoo, Michigan 49008, USA \\ K. Heller, P. Heller, and V. Kuo ${ }^{\dagger}$ \\ School of Physics and Astronomy, University of Minnesota, Minneapolis, Minnesota 55455, USA
}

(Received 28 October 2005; published 12 December 2007)

\begin{abstract}
In higher education, instructors' choices of both curricular material and pedagogy are determined by their beliefs about learning and teaching, the values of their profession, and perceived external constraints. Dissemination of research-based educational reforms is based on assumptions about that mental structure. This study reports the initial phase of an investigation of the beliefs and values of physics professors as they relate to the teaching and learning of problem solving in introductory physics. Based on an analysis of a series of structured interviews with six college physics faculty, a model of a common structure of such beliefs for all physics faculty teaching introductory physics was constructed. This preliminary model, when tested and modified by future research, can be used by curriculum developers to design materials, pedagogy, and professional development that gain acceptance among instructors.
\end{abstract}

DOI: 10.1103/PhysRevSTPER.3.020109 PACS number(s): 01.40.Fk, 01.40.G-, 01.40.J-, 01.50.Kw

\section{INTRODUCTION}

Although significant curriculum development efforts for at least four decades have produced materials and techniques that have been shown to be more effective than those typically in use, they have had only a minor effect on the teaching of college-level physics. ${ }^{1-4}$ Even the most effective curricular materials, tools, and pedagogies must be accepted by instructors if they are to become routine practice. This is particularly true in higher education, where academic freedom gives faculty members a great deal of autonomy in choosing both a curriculum and its teaching. It is curious that this autonomy does not seem to give rise to a vast variety of idiosyncratic introductory physics courses. Indeed, there appears to be a uniform and stable set of educational practices in the teaching of introductory college physics that have been characterized as traditional instruction. ${ }^{1}$ New instructional ideas, such as those based on research in learning, must compete with these longstanding traditional methods.

In terms of the marketplace, improved educational products must gain customer acceptance if they are to displace widespread traditional practices. In the commercial world, product designers know that to gain market share, they must construct their product to match the customer characteristics that influence their choices. Following this model, the first step of effective dissemination of curriculum or pedagogy developed by physics education research must occur in the design process. Acknowledging the knowledge, beliefs, and values, as well as perceived needs and skills that underlie an instructor's choice of curriculum and pedagogy is a prerequisite to achieving a design that can be efficiently disseminated. [Many researchers have decided that making the distinction between different aspects of teacher's thinking is neither possible, nor useful (see, for example, Ref. 5). In this paper, we will use the terms beliefs or belief structure to refer to a general mental structure that involves knowledge, ideas, beliefs, values, mental images, preferences, and similar aspects of cognition.]

The purpose of our research is to begin the process of building a model to describe the beliefs of physics faculty that influence their choice of curricular materials and pedagogy when they teach introductory physics. It is anticipated that this model can be used to formulate a set of testable hypotheses that will lead to an elaborated and corrected model with features that can be applied to curriculum and professional development. The study reported here focuses on the beliefs of physics faculty about the teaching and learning of problem solving in the context of a calculusbased, introductory physics course. In particular, this study investigates instructor beliefs that might affect their decisions to use research-based curricula that guide students to develop expertlike problem solving, which functions as a primary mode of learning introductory physics. ${ }^{6-11}$

A common feature of these research-based curricula ${ }^{12}$ is the use of a cognitive-apprenticeship instructional approach. ${ }^{13-16}$ To implement this approach, instructors model explicitly a general problem-solving framework that is implicit in the problem-solving approaches of experts, ${ }^{15}$ students attempt to solve problems within this framework while being coached, and students practice using this problemsolving framework on their own. Students regularly reflect on the modifications that they made to their initial problemsolving process. Even though data shows that these researchbased curricula achieve their goals, ${ }^{8,17}$ only a minority of the instructors who profess to emphasize problem solving in their courses adopt them. 


\section{BACKGROUND}

\section{A. Beliefs of college faculty}

A number of researchers have investigated the general ideas of teaching held by college instructors. ${ }^{1,2,18-20}$ All of these studies result in a hierarchical list of different ways that the instructors understand teaching. The lists differ in detail, but they range from teacher-centered ideas of learning, resulting in instruction emphasizing the transmission of knowledge, to student-centered ideas tending toward the constructivist approach. There is some research on instructors' views about learning and teaching in the context of physics problem solving. In one study, 24 Australian physics and chemistry instructors were interviewed about issues related to their ideas of teaching and learning in first year university science classes. ${ }^{21}$ Seventeen of these instructors talked explicitly about problem solving. This data indicated that instructor beliefs about problem solving were correlated with their ideas about teaching. Instructors who thought of problem solving as an application of existing knowledge held more teacher-centered views of teaching, while instructors to whom problem solving was about making sense of the problem held more student-centered views. University physics and chemistry teachers who taught service courses were more likely to have a teacher-centered idea of teaching than those who taught graduate students. ${ }^{2,18}$ Other studies on physics instructors, however, report very different conclusions. $^{4,22}$ For example, one study reported that physics instructors believed that the introductory physics course was primarily a framework for students to develop their individual intellectual skills. ${ }^{22}$ Unfortunately, all of these studies are too general to provide much information useful to curriculum developers.

\section{B. Beliefs of K-12 science teachers}

Studies of K-12 teachers found that their beliefs were not necessarily reflected in their classroom practice because conflicting ideas often arise when teachers consider a possible instructional activity from different perspectives. ${ }^{5,23-25}$ For example, one study of $107 \mathrm{~K}-12$ science teachers found that teachers believed that including cooperative learning in the classroom could help increase student learning, make science more interesting, increase problem-solving ability, and help students learn cooperative skills. ${ }^{25}$ But they also believed that the use of cooperative learning would increase student off-task behavior and take up too much class time. The study found that the concern for off-task behavior was the best predictor of a teacher's intention to use cooperative learning. A study of eight Israeli high school physics teachers regarding their ideas about the learning and teaching of problem solving revealed that they were aware that students needed to develop processes for problem solving, yet their ideas about instruction did not include the development of those processes. $^{26}$

Research about teachers' decision-making process shows that they draw upon tangled and occasionally conflicting conceptions. ${ }^{5,23-25,27}$ Teachers' decisions seem to be shaped by a constellation of beliefs, goals, knowledge, and action plans. ${ }^{28}$ Each decision depends on the immediate context, interpreted in light of former experiences. Much of an experienced teachers' decision making is automated, and the teacher is no longer aware of the reasons that led to its development. ${ }^{29-32}$ To collect meaningful data about teaching and learning beliefs, these studies found it necessary to develop tools that probe teachers' ideas at different levels and from different directions.

An effective data collection tool to study a teacher's beliefs about teaching and learning was to ask them to make decisions in actual or simulated teaching environments. ${ }^{29-34}$ This tool was found to be superior to observing them teach because they could be asked to "think aloud" and explain their interpretation of events and resulting decisions in real time. This technique is similar to the methodology used in many studies of students' conceptions of scientific phenomena. ${ }^{35-40}$ In these studies, students are asked to interpret and explain specific events, usually using concrete artifacts. The researchers infer student ideas from these responses.

\section{Dissemination models}

The lecture/demonstration mode of teaching used by a vast majority of physics faculty, especially when teaching introductory physics, appears to imply a transmission model of teaching and learning: the instructor carefully explains a concept or technique, sometimes using examples or demonstrations, and the conscientious student understands and can use that idea or technique. ${ }^{41}$ Their students then practice, do homework, until that usage becomes automated. Dissemination efforts for new curricular materials or pedagogical techniques often begin by attacking that transmission model and developing a rationale that favors a constructivist view of teaching and learning, which is the hallmark of many reform curricula. The constructivist view proposes that each student constructs his or her own knowledge by interpreting instruction in terms of their existing knowledge structure and changing parts of that knowledge structure. ${ }^{42}$

A common type of dissemination seeks to create a cognitive disequilibrium between the instructor's teaching goals, their assumed schema of transmission as teaching, and evidence of student performance that traditional instruction does not meet the goals. This disequilibrium is then resolved in favor of a specific constructivist approach. The activities incorporated into this type of dissemination are based on the assumption that faculty teach in a mode that emphasizes the transmission of information because they believe that this is an effective mode of teaching and learning or that they value this mode of instruction. However, physics instructors often revert to traditional teaching practices, even when they attended professional development sessions that take this approach and use the new curriculum in their classrooms. ${ }^{23}$ This is true even when the instructional support for the new curriculum exceeds that available for traditional materials.

The observation of transmissionist instructional practices does not, however, necessarily mean that these instructors have transmissionist beliefs about teaching and learning. In fact, several studies suggest that dissemination activities aimed at teachers' assumed transmissionist beliefs have not 
produced widespread instructional change in $\mathrm{K}-12$ teachers because of the complicated and sometimes inconsistent nature of teachers' beliefs. ${ }^{5,24,43-46}$ Although less research exists for college instructors, data indicate that they are similar to $\mathrm{K}-12$ teachers in this respect. ${ }^{23}$ Other findings suggest that instructors' beliefs color their perception of classroom events so that what they are actually doing is not necessarily what they intend to do. Even when some instructors use a constructivist curriculum, their practice often alters its original intent. ${ }^{47-52}$

If college faculty also have a complex belief structure for instruction that is not necessarily internally consistent and not determined by large overarching schemas, then there are three strategies to disseminate effective instructional models. In order of their implementation difficulty from easiest to more difficult, these strategies are:

(1) Design new curricular materials and their accompanying pedagogy to be as consistent as possible with existing instructor beliefs and avoid conflict with strongly held beliefs.

(2) Design short professional development workshops to reinforce faculty ideas that align with the proposed curricula, while weakening undesirable beliefs by pointing out internal conflicts and using the standard methods of persuasion to support the desired beliefs.

(3) If the instructional design violates key instructor beliefs and practice, design a thorough professional development to accompany and support a long term process of change.

In all cases, it is first necessary to determine the faculty belief structure that underlies their instructional decisions.

\section{RESEARCH QUESTIONS}

This study is the initial step in building a model of the common underlying belief structure of university and college physics professors with respect to the use of problem solving when they teach introductory physics. The first, and most important, issue for this line of research is to determine whether there is a limited set of belief structures that can describe most physics faculty. It is possible that instructors do not have a common core of beliefs with respect to teaching and learning, since they have no formal education in this domain and typically do not discuss their teaching beliefs with colleagues. On the other hand, it is possible that instructors do have a common core of beliefs about teaching because they received their education from a limited group of universities at which they had similar educational experiences.

If there is a common core, then our initial model of this core should encompass three general features of an instructional system: ${ }^{53}$ (1) the initial state of the students with respect to their knowledge and skills in solving physics problems, (2) the desired final state of the students, and (3) the instructional processes necessary to accomplish the transformation from the initial to the final state. This systems approach commonly underlies research-based curriculum in physics problem solving. ${ }^{6-11}$ We should be able to represent the complex interrelationships among instructor beliefs and discriminate between strongly held and fragmented or even conflicting beliefs. Hence we should answer the following questions:

(1) What do instructors believe students should do when solving problems?

(2) How do instructors believe students should learn in the context of problem solving?

(3) What prerequisite knowledge or skills do instructors expect of their students?

(4) How do instructors characterize their students' actual learning and problem-solving practices?

(5) How do instructors believe they could help students' learning in an optimal situation?

(6) What do instructors think limits their instruction?

(7) How do instructors weigh their values, beliefs, and perceived constraints to arrive with their actual instruction?

As additional guidance for the curriculum developer, it is useful to know how instructor beliefs align with the assumptions that underlie research-based curriculum and with the standard instructional paradigms, ${ }^{16}$ behavior, developmental (constructivism), and cognitive apprenticeship.

\section{METHODOLOGY}

Considerable measurement and analysis challenges face researchers investigating the beliefs that influence the instructional decisions of physics faculty. Observations can be misleading because a person's practice reflects their resolution of many different and potentially conflicting ideas. Indeed, observation of people's behavior is typically not useful in determining the necessary elements for changing that behavior. Questions about beliefs, whether written or oral, often do not uncover unanticipated or implicit ideas that might underlie decision making. General interviews about beliefs, in which the interviewer explicitly probes for those ideas, can give results that are biased by the belief structure of the interviewer. For this study we drew on the techniques of ethnography, ${ }^{54}$ particularly as applied in policy capturing techniques, ${ }^{55}$ to design artifact-based structured interviews. We also drew on the grounded theory approach to qualitative research ${ }^{56,57}$ for analysis principles such as the constant comparison method of inductively developing emerging categories and their relationships from the available data. Of course, any interview risks biasing the data by imposing the interviewer's expectations on the discussion; hence the data collection and analysis tools were carefully designed to bring out the authentic views of the interviewee. A brief overview of the methodology is described in the following sections, and a full description is provided in the companion paper. ${ }^{58}$

\section{A. Data collection}

The interview encouraged introspection by asking for a comparison among artifacts. We used specific familiar instructional tools as artifacts. Those artifacts, shown in the companion paper, ${ }^{58}$ were built from actual materials used by 
physics faculty while teaching introductory physics. All of the artifacts were built around a single physics problem that was given to students on an introductory, calculus-based final examination. The problem was sent to each instructor before the interview and they were asked to solve it as preparation for the interview. The artifacts for the interview consisted of five different versions of the same problem, three different instructor example solutions for the problem, and five different student solutions. The artifacts, although based on authentic documents, were constructed to reflect the range of instructor practices. They were also designed to reflect differences between: (1) traditional and research-based curricula in the arena of problem solving $;^{59,60}$ and (2) the three basic instructional paradigms, ${ }^{16}$ behavior, developmental (constructivist), and cognitive apprenticeship. The method of using comparison tasks aims to focus the discussion and elicit implicit beliefs, hence minimizing the randomness of the interviewees' commentary. Another advantage of comparison tasks is that they use only natural language and avoid "leading questions" that might bias the responses.

The interview took about 1.5 hours to administer and had four parts. The first three parts dealt with different instructional situations: (1) the instructor assigns a problem to students; (2) the instructor grades a student's solution; and (3) the instructor presents students with an example problem solution. To minimize subjectivity, an initial plan for interviewer interventions was predefined and scripted. The interviewer added probing questions to make sure the interviewee answered the predefined questions. In each part of the interview, general questions were asked about how and why the instructor might use a specific type of artifact and how the artifacts compared to the materials actually used in their classes. The interviewee was also asked to reflect on the problem-solving process as represented in these artifacts.

During the interview, the interviewer wrote on index cards each feature of the problem-solving process that the instructor mentioned. In the last part of the interview the instructor was asked to group these index cards into categories of their choosing and name the categories. The interviewer then asked several questions regarding these problem-solving categories to determine if the instructor thought they were reasonable to expect of their students, how instructors thought that students could overcome any difficulty they had with them, and how the instructor could help students with these difficulties. Finally, instructors were asked about their satisfaction with their current course. Triangulation was accomplished by comparing the interviewee's statements among the different types of artifacts and with the final classification task. Both the audio and visual content of the interview was recorded on video and the audio portion was transcribed.

\section{B. Sample}

The results presented in this paper are based on interviews with six instructors. These instructors were randomly selected from a pool of 23 instructors from the University of Minnesota who had taught the introductory, calculus-based physics course at least once in the past 5 years. This group was chosen as a calibration group for the study because their instructional behavior was known. A group from a single institution was chosen to form an initial model because they had the largest chance of having coherent beliefs about teaching and learning. All of the participants were male. They had a broad range of teaching experience (2-43 years), as well as experience teaching the introductory calculusbased course (1-79 times).

These instructors teach at a research university with an active physics education research group. During the previous 12 years, this research group had introduced significant changes to the introductory, calculus-based physics course, ${ }^{8,9,61}$ while leaving the underlying structure of lectures, discussion sections, and laboratories in place. These changes have been shown to be effective in improving students' problem-solving skills as well as their understanding of physics concepts, ${ }^{8,9,62}$ and continue to be the framework of all introductory physics instruction in the department. Although the teaching assistants (TAs) for these courses receive instruction and support for teaching problem solving in cooperative groups, ${ }^{62}$ the professors did not.

No constraints were put on the professor about how lecture time should be used. They were responsible for meeting with their TAs weekly and organizing the laboratories and discussion sections as well as their lectures for their course. Although various changes in the role of the professor had been suggested and modeled within the department, almost all faculty conducted their lectures in a manner that would be described as "traditional." Observations of these instructors, including one detailed study, ${ }^{63}$ confirmed that their style of teaching was best characterized as transmission. Nevertheless, it is likely that the instructors interviewed for this study are more knowledgeable about the teaching and learning of problem solving than instructors at other institutions because of their exposure to the curriculum implementation activities of the physics education research group.

\section{Data analysis}

Analyzing the rich data derived from the interviews posed several challenges, the first of which was to determine how to efficiently represent the complex interrelationships among the instructor beliefs underlying the interview narrative. To address these challenges, we developed an analysis technique involving a version of open coding ${ }^{57}$ to construct multilayered concept maps. This analysis technique is described briefly below, and in more detail in the companion paper. ${ }^{58}$

The analysis consisted of the following four steps.

(1) Each instructor's interview transcript was broken into statements ${ }^{64}$ that addressed one or more of the predefined research questions. This step was performed independently by at least two members of the analysis team until an agreement rate of $93 \%$ was achieved. Each of the interviews yielded approximately 400 statements.

(2) A tentative concept map ${ }^{65}$ was constructed from the transcript statements of the six instructors. Each box represented a principal category of an instructional system ${ }^{53}$ for the learning and teaching of problem solving; the links (arrows) between the boxes represented the relationship between these categories that we found prominent in the transcripts. We call this the "main" map. 
(3) Individual concept maps were constructed for each instructor to elaborate each principal category on the main map. All statements related to each principal category were sorted and categorized via confined open coding. ${ }^{58}$ Analysis was constrained by the research goals by matching instructor statements to the tentative main map whenever possible. It was still, however, an open coding process $^{57}$ where instructor-generated categories and connections were allowed to emerge. Thus the main map and the individual concept maps were modified as new categories or connections were uncovered in the analysis of other instructor's transcripts.

(4) For each principle category, a concept map was constructed to represent the commonalities and differences of the concept maps of each instructor. We called these "composite" maps (see Fig. 2).

Each step included a validation process in which at least one additional researcher returned to and reinterpreted the original statements used to build a map. The entire research team discussed and resolved all disagreements. This process resulted in the iterative revision of the concept maps until all statements of each instructor fit into all of the composite maps.

It is important to keep in mind that, although the boxes (representing the principal categories) and the connections between them (represented by links between boxes) came directly from the interview data, this organization is a construct of the analysis process. The organizing structure shown in the maps was not provided explicitly by the interviewees. They did not necessarily directly express either the main ideas on the maps, nor their connections. Consequently, the maps should not be read as evidence of a conscious organization of the beliefs of any specific instructor. It is unlikely that any of the individuals interviewed envisioned the entire picture of their belief structure.

\section{RESULTS}

The composite concept maps are the most direct representation of the results of this study. Taken together, they represent a model of the underlying beliefs about the role of problem solving held by the population of physics faculty teaching introductory calculus-based physics. The concept maps show those factors that faculty believe are important (the boxes), and how these factors are linked (the lines). In cases where there might be more than one major set of beliefs in the faculty population, the maps show the alternatives. In Sec. A-H below we give interpretations of the concept maps with respect to the seven research questions that motivated this study. We have also included some of the raw data to illustrate the basis of these interpretations.

\section{A. Overview of instruction and learning}

The main map, shown in Fig. 1, is a model of the common underlying belief structure of university and college physics faculty with respect to using problem solving when they teach introductory physics. This map is the initial step in building testable hypotheses addressing the categories and links of the model. Clearly, the main map and its associated composite maps are influenced by the structure of the interview and the analysis. However, because the main map reflects the instructors' discourse in relation to the questions and artifacts of the interview, we believe that such a map, when tested and modified, will be a useful representation of the underlying pattern of common instructor thought that must be respected in any attempt at curricular change. By explicitly showing a model of these beliefs and how they are linked, the specifics of the map can be tested by more directed experimental means. By using the iterative analysis technique described in the companion paper, ${ }^{58}$ we found such a large degree of similarity that we were able to build a common main map as well as composite maps that illustrate prevalent instructor similarities and differences.

The most important conclusion of this study is that these physics faculty have a very similar belief system about the teaching and learning of problem solving in their introductory physics classes. The instructors' belief system is most closely aligned with extreme constructivist learning theories. This is not to say that any of these instructors have a carefully constructed "teaching philosophy." As with any human thought, instructors' belief systems have parts that are internally inconsistent and reveal gaps where parts do not obviously connect to other parts. Although instructors have a large overlap in their belief systems, they are not identical. Some important characteristics of the main map are described briefly below. Further elaboration is provided in the following sections $(\mathrm{B}-\mathrm{H})$.

\section{Typical students' learning practices differ dramatically from those required for the course}

At the top of the main map are two boxes (principle categories) focused on students' characteristics: the category "Students Who Can Improve" (elaborated in Fig. 7) and the category "Typical Students" (elaborated in Figs. 8 and 9). The category "Students Who Can Improve" and its links shows that the instructors do not expect their actions to influence all students in their classes. Instructors usually exclude students who can learn without instruction and those who do not have enough "natural ability" to learn with instruction. Most instructors believe that, while most students in their class are intelligent enough to construct the "Appropriate Knowledge" (Fig. 3), only a fraction of those actually do so. These target students, who do improve meaningfully, are those that enter the course with the motivation to work hard, are confident about their ability to learn in the course, and have good study habits, namely an ability and inclination to be reflective.

The "Typical Students" composite map describes the instructor beliefs that typical students' learning practices differ dramatically from those that they think students need for the course. In general, instructors believed that typical students have poor problem-solving skills and detrimental learning characteristics. In particular, they thought that typical students did not engage in reflective learning. One instructor explicitly described this mismatch by contrasting the typical student with his target audience: 
"The [typical] students who are required to take the physics course and reject it as much as they can and are happy if they pass are the kinds of students I have to deal with-they are the bread and butter of the department...they're not going to work hard... they're just riding along." [I2, 42, 37]

"I am mainly interested in the students who respond to the class." $[\mathrm{I} 2,40]$.

The notation [I\#, \#] denotes [Instructor identification number, Transcript statement number].

\section{One learns problem solving by being reflective, yet reflectivity is beyond the scope of the course}

Problem solving was discussed by the instructors in two distinct ways: in the box "Solving Physics Problems" (Fig. 2) as a worthwhile activity on its own, that serves as a goal for the course; and in the box "Work" (Fig. 4) as the principle tool to reach many of the other course goals. The "Solving Physics Problems" composite map represents the problem-solving process that instructors hope the students they target will be able to perform at the end of the course. The goals of the course, as presented in "Appropriate Knowledge" composite map (Fig. 3), included the correct understanding of physics concepts as well as effective problemsolving approaches and techniques. The central belief of the instructors was that students learn to solve problems by engaging in problem solving and reflecting on it. All instructors thought students should also "Use Feedback" (Fig. 5) or "Look/listen" (Fig. 6) to the instructor's "Appropriate Example Solutions" (Figs. 11 and 14). But they did not believe that students can learn problem solving solely by these actions. Reflectivity was brought up as a specific way of working, using feedback or watching someone demonstrating problem solving, that is required to fully utilize these experiences to construct the appropriate knowledge. Even though all the instructors mentioned a category of reflective skills (self-evaluation) as a prerequisite for learning using problem solving, they viewed this skill as beyond the scope of an introductory physics course. Nevertheless, the instructors estimated that a majority of the students attained most other categories of appropriate knowledge by the end of the course.

\section{Instruction is not designed to promote reflectivity, which is required for learning}

Instructors were viewed as either: (1) providing resources, such as problems for students to solve and instructorgenerated example problem solutions, (2) imposing constraints on students (e.g., grading homework), or (3) giving suggestions on how to approach learning and solve problems effectively. The main map shows a link between the "Typical

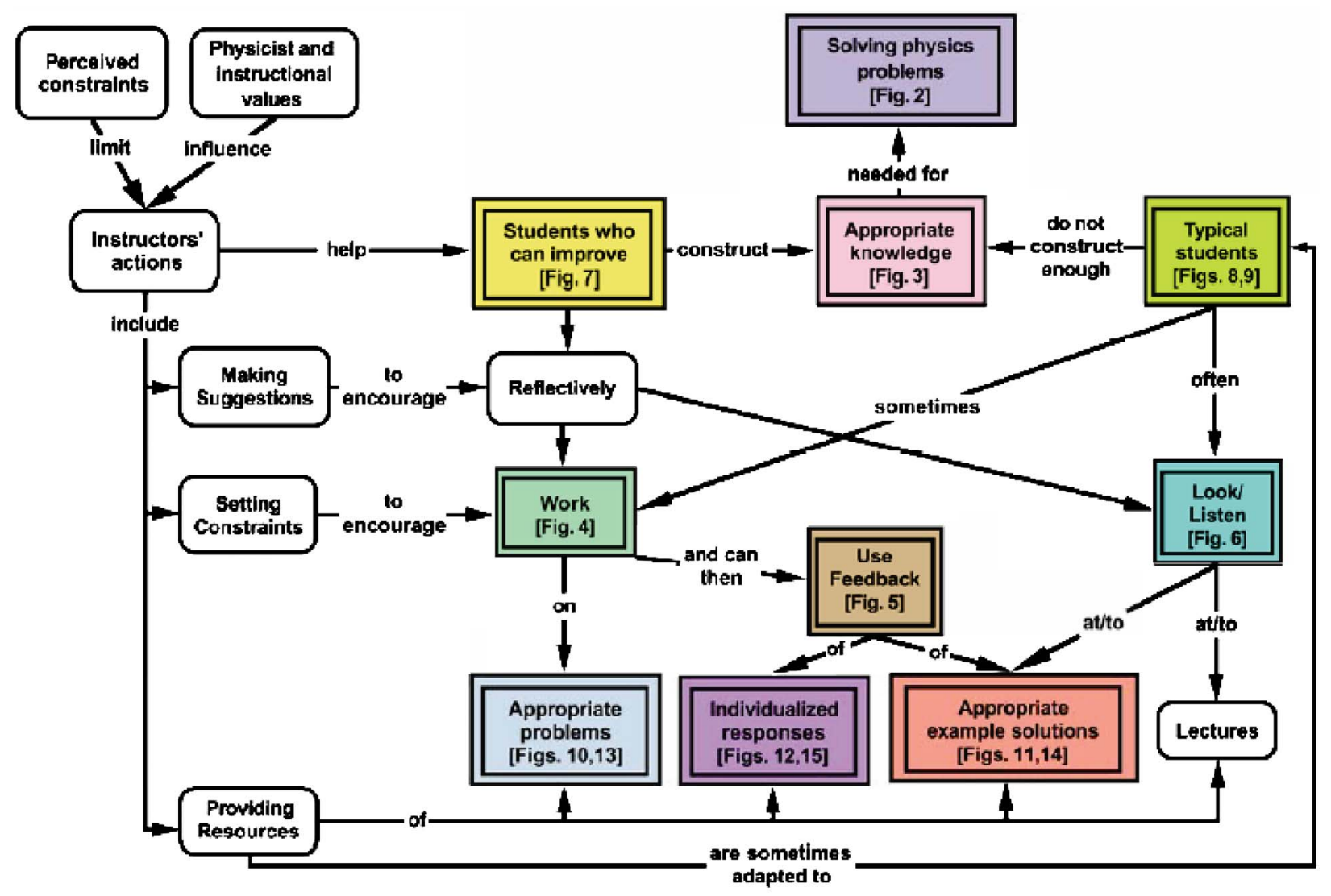

FIG. 1. (Color) Main map of faculty beliefs and values about learning and teaching problem solving in an introductory physics course. Boxes and links on the main map are common to all six instructors. The boxes framed with a double line indicate principal categories that are elaborated in separate composite map figures, as indicated. 
Students" box and the instructors' actions, reflecting that the resources that instructors provided were, they believed, adapted to some extent to accommodate the typical student characteristics. For example, the belief that entering students could solve only one-step problems led some instructors to assign only one-step problems at the beginning of the course. In their lectures, instructors reported that they occasionally told students to work reflectively. They did not constrain them to do so, even though they believed learning requires reflectively engaging in problem-solving activities, and that typical students do not have reflective skills.

Instructors' ideas of appropriate teaching actions were determined primarily by their values in the domain of physics, their beliefs of how students might react negatively to alternative actions, and their recognition of their own limitations. For example, although they thought students would learn better from example problem solutions that contained more explanation of expert thought processes, they refrained from constructing these solutions for three reasons: (1) their physics values directed them to not stifle student creativity in problem solving by providing solution examples that were too detailed; (2) they believed that students would be frightened by problem solutions showing too many steps; and (3) they did not have the time to construct such solutions. Several instructors also expressed the belief that they did not have the knowledge required to make up "good" problems, which they believed would differ from those in the textbook.

The following (Secs. B-H) is an elaboration of these results that address the research questions posed in Sec. III.

\section{B. What do instructors believe students should do when solving physics problems?}

Our model about what instructors believe their students should do when solving physics problems comes from two data sources: (1) the components of problem solving that the instructors described when they looked at and discussed the interview artifacts; and (2) the categories of problem solving that instructors provided in the final part of the interview, when they sorted their own problem-solving components into categories. When discussing the interview artifacts, instructors typically described the components of problem solving as elements of a "process." We grouped these components in the box "Solving Physics Problems" (Fig. 2).

During the final part of the interview, after the instructors had sorted their problem-solving components into categories, they were also asked: "Which of these things (categories) is it reasonable to expect most students to be able to do by the end of the introductory, calculus-based physics course?" and "Where are your students regarding these categories when they enter the course and in the end of the course?" these questions assumed that some of their problem-solving categories function as goals. This assumption was supported by the fact that the instructors estimated to what extent their students' achieve some of the categories. When they felt a category was not actually a goal of their course, they said so. We grouped the goal categories (represented in uppercase) in the "Appropriate Knowledge" box, Fig. 3. Each of these views, problem solving as a process and problem solving as a course goal, are described below.

\section{Problem solving as a process}

Three instructors described the process of solving physics problems as a linear decision-making process, two believed it was more of an exploration process, and one had a mixture of both.

The linear decision-making process was described by three of the six instructors and involved the following stages.

(a) Stage 1. Identifying the relevant physics principles and concepts:

"Dealing with a problem is standardized into a number of steps: a, what are the physical principles that operate in this situation." $[\mathrm{I} 2,84]$

For some, this identification entailed first categorizing the problem and than retrieving pieces of knowledge related to the category.

"Having categorized a problem, the category then brings up to me a bunch of stuff related to the category." $[\mathrm{I} 5,77]$

We found that the categorization could involve either physics concepts or surface features, and the phrasing of the related pieces of knowledge was sometimes vague and potentially misleading.

"For example, in a potential energy problem, generally you have to match the potential energy to the kinetic energy or something like that." $[\mathrm{I} 5,77]$

"They'll look at it and say 'Hey, that's like these loopthe-loop problems.' These problems are nice because it's always a normal force and the normal force is always perpendicular to the direction." [I3, 119]

The recognition process can take a systematic hierarchical structure, and can be facilitated by a visual representation of the problem situation.

"I think that a lot of solving physics problems can be enhanced by essentially using some sort of tree structure in their thought process." $[\mathrm{I} 5,73]$

"I can draw a diagram to clarify my thinking." [I2, 84]

(b) Stage 2. Applying specific techniques: "Combining these (drawings principles) into a mathematical form that can come up with the final answer." $[\mathrm{I} 2,84]$

(c) Stage 3. Evaluation of the answer: "I encourage students to check dimensions; I would say 'make sure you have a force when you're done with this thing'." [I3, 11]

The exploration process was described by two of the six instructors and involved coming up with possible choices and then testing them.

"In solving a problem you need to have some vague idea in your mind about what you need to do and then come up with the explicit tools." [I1, 103]

"You're often playing around with it for a while to see what approaches might be valuable if you're not an expert at it." [I6, 147]

Making mistakes and having to backtrack and clarify under- 


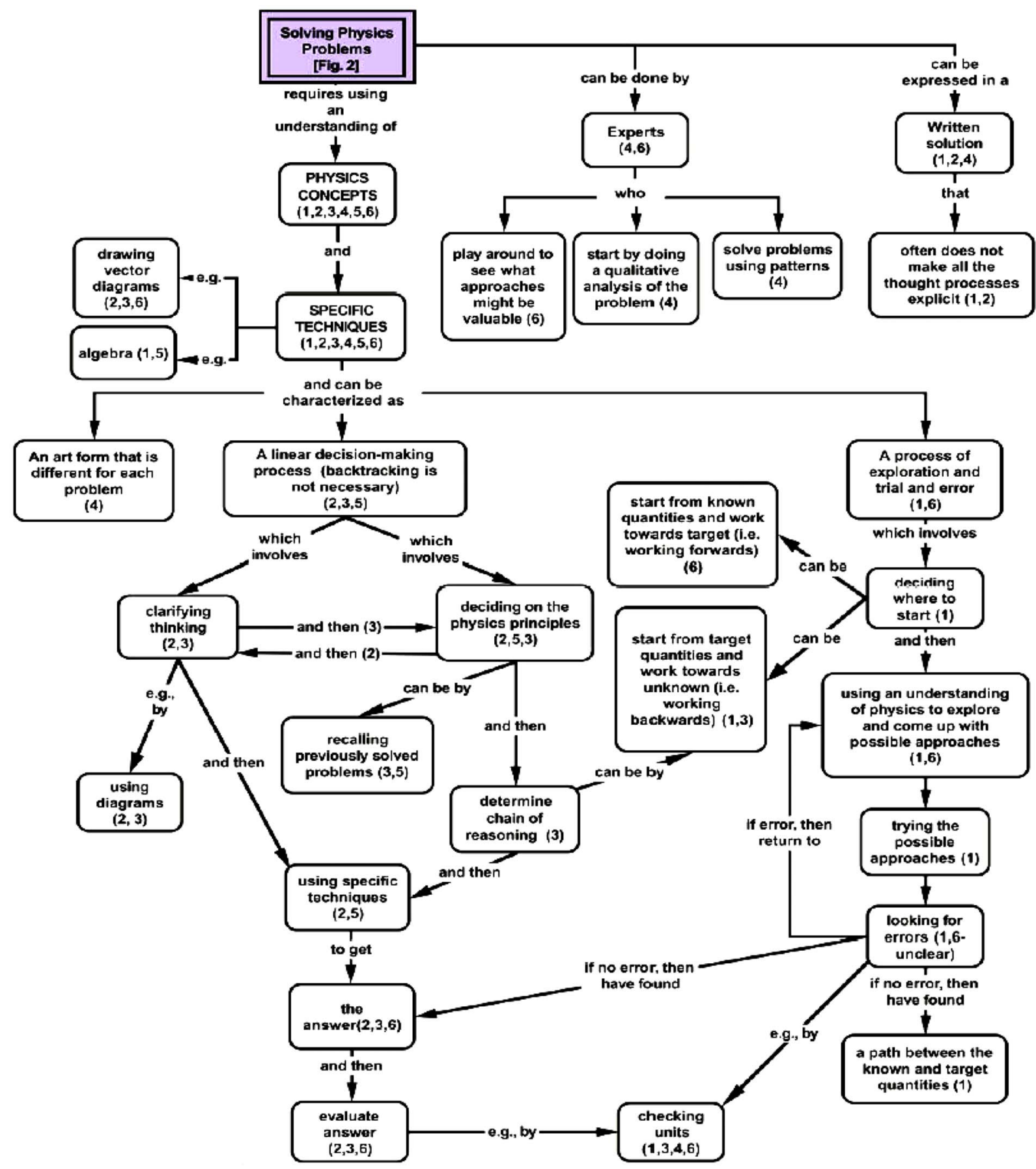

FIG. 2. (Color) "Solving Physics Problems" composite map of faculty beliefs about the problem-solving process in an introductory physics course. Numbers in the parentheses denote the instructor whose statements directly justify that category. Uppercase labels refer to specific types of knowledge that also occur in the "Appropriate Knowledge" composite map shown in Fig. 3.

standing is a natural part of problem solving. For example:

"Solving a problem is not a logical process-there's something that you have to guess and then use trial and error." [I1, 28]

The sixth instructor described the problem-solving process as artfully crafting a unique solution for each problem:

"Solving physics problems is an art and we should think of it as an art... . Each physics problem has a kind of style to it, a gestalt to it." [I4, 101]

Yet he also shared some features of the other two perspec- 


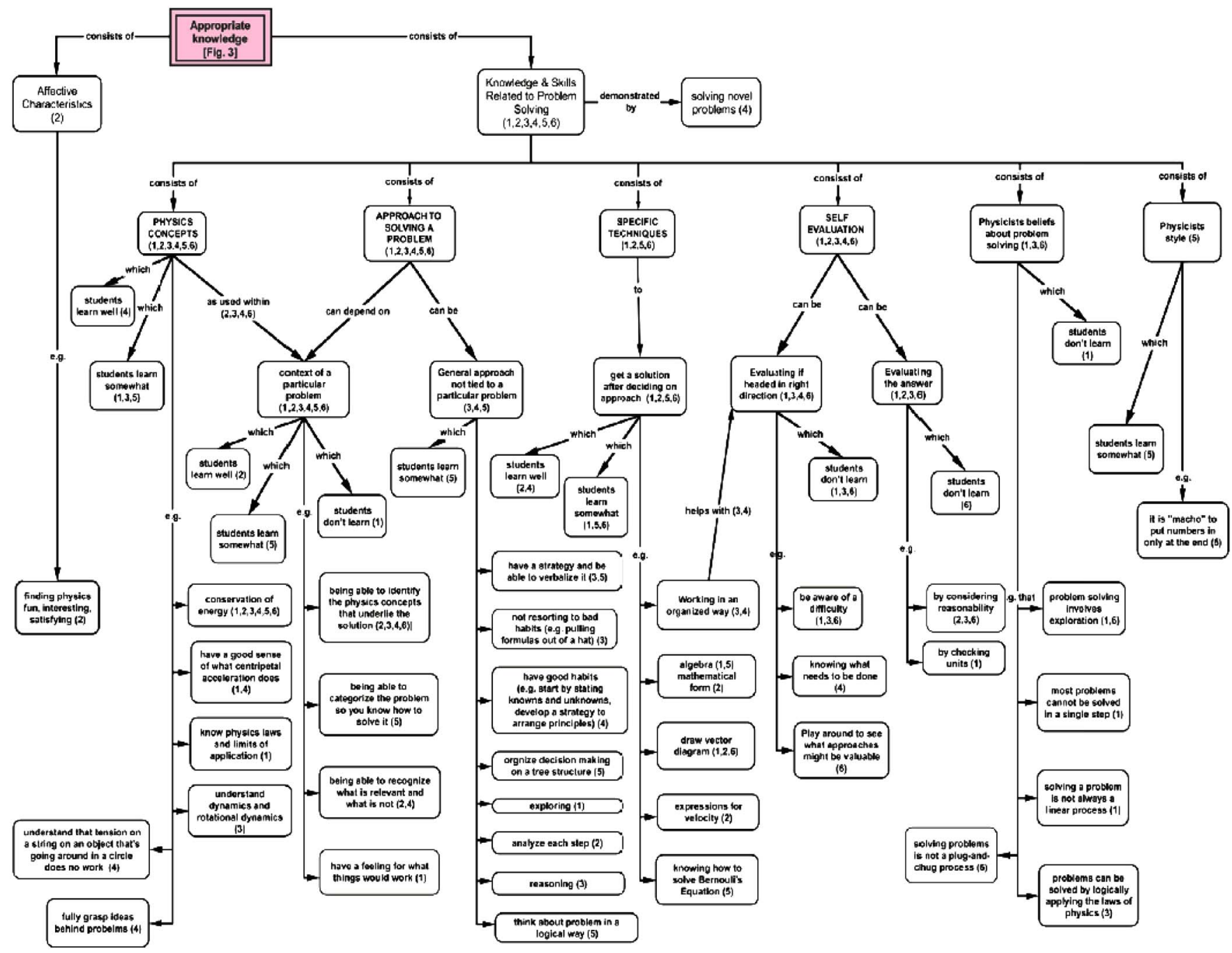

FIG. 3. (Color) "Appropriate Knowledge" composite map of faculty beliefs about problem-solving goals in an introductory physics course. Numbers in the parentheses denote the instructor whose statements directly justify that category.

tives. He had the exploration idea that evaluation and backtracking is part of problem solving:

"I favor for the students to leave quantities in symbolic form until the end. That will enable them to spot errors. If something doesn't make sense, they can spot the symbolic forms of these things and, for example, look at the dimensions and see whether they make sense." $[\mathrm{I} 4,69]$

He also believed that you start a solution process by connecting specific situations to general physics principles.

"Another tool that you want to carry with you, which I think a reasonably sophisticated student would realize, is that one of the clichés is that tension on a string, on an object that's going around in a circle, doesn't do any work. The motion is at right angles to the force." [I4, 36]

The difference between the instructors who believe their students should solve problems by a linear process and those who believe their students should use an exploration process appears to be the expectation of the success that the students will have at each step of the problem-solving process. At one extreme, instructors who want their students to follow a linear process believe their students should make the correct decision from one step to the next. At the other extreme, the instructors who believe their students should follow a process of exploration assume that each student decision might be incorrect. For these instructors, exploration is necessary to make a correct choice from a collection of possibilities. They do not envision students employing an organized procedure that will limit choices and determine when important decisions must be made.

\section{Problem solving as course goals}

The problem-solving categories that function as goals for the course are shown in the map "Appropriate Knowledge," Fig. 3. They yielded four different types of appropriate knowledge that most instructors shared. In the following, instructor statements written down by the interviewer during the interview for use as the final artifact in the interview process are not given transcript numbers. 
(1) The APPROACH TO SOLVING A PROBLEM category was shared by all instructors. They labeled this category as "Overall Approach/Philosophy" [I1], "Strategy" [I2, I3], "Organizing work" [I4] or "General approach" [I5]. Instructors included in this category items of the following types.

(a) Initial analysis of the problem: Translating English statements to physics/math equations [I1], Summarize knowns and unknowns at beginning [I4], Identify physics in a problem situation [I3], and Categorize the problem [I5].

(b) Devising a plan: Break the problem into steps [I1]; Assembling steps [I2]; Follow some strategy [I3]; Develop a strategy to arrange principles [I4]; Organize decisionmaking on a tree structure [I5]; Identify physical concepts [I3], and Categorize problems [I5].

(c) Thinking over the plan: Explore yourself what you can do with physics ideas [I1]; Analyze each step [I2]; Reasoning process [I3]; and Think about problem in a logical way [I5].

(2) The category "PHYSICS CONCEPTS" was shared by all instructors. It was labeled so by $\mathrm{I} 3$, and also as "Understand Physics" [I1, I6] or "Big Principles" [I4, I5]. It included items like Knowing conservation of energy [everybody], Know physics laws and limits of application [I1].

(3) The "SPECIFIC TECHNIQUES" category was shared by four instructors. It was labeled so by instructors I1 and I5, and also called "implementation" [I2] and "procedural" [I6]. It referred to a student's ability to perform technical processes after deciding on a path to take while solving a problem. Instructors included in this category statements such as Good algebra skills [I1], Substitutes to get answer [I2], Draw vector diagrams [I6].

(4) The SELF EVALUATION category was shared by five instructors. It was labeled by them as "Big Picture Technique" [I1], "Perspective" [I2], "Signs of Maturity" [I3], and "Hope students do" [I6]. It included statements that refer to an ongoing evaluation of the process: Need to evaluate if right direction [I1], Recognize when something is missing [13], Have a doubt when unsure, and Play around to see what approaches might be valuable [I6]. It also included the evaluation of the final answer: Translate back to see if meaningful [I2], and Realize that final result is large [I6].

Another category was not explicitly defined by the instructors in the card categorization process but emerged when analyzing the transcripts. Three of the instructors included in their discourse on appropriate knowledge statements concerning professional physicist beliefs about problem solving.

(5) The professional physicist beliefs category about problem solving includes the understanding that problem solving involves exploration and that most problems cannot be solved in a single step: "this idea that there's an exploratory process to do it is a professional type approach to do this sort of thing" [I6, 255].

All instructors, whether they expected their students to use a linear or an exploratory problem-solving approach, desired that their students use strategic problem-solving skills such as initial analysis, planning, and self-evaluation. They believed that most of their students did not have these skills when entering the course, and only had a partial grasp of them by the end of the course. However, none of these instructors expressed the students' need to learn these strategic problem-solving skills when faced with our artifacts. Their recognition that students needed to learn strategic problemsolving skills only surfaced when the instructors were asked to sort their previous statements about problem solving. From this we infer that the instructors' belief that their students need to learn such skills was not strongly linked to their beliefs about teaching actions.

\section{How do instructors believe students should learn in the context of problem solving?}

All instructors believed that the primary way students learn problem solving in introductory physics is by working on problems. The composite map "Work" (Fig. 4) includes instructors' beliefs regarding using problem solving as a process directed at learning. This information comes primarily from three places in the interview process: statements that they provided when reacting to the different interview artifacts; response to the interviewers' prompting about the difficulties students had with each of their sorting categories; and their goals as stated in the final part of the interview.

All instructors expressed the belief that a student can get the appropriate knowledge by working problems, typically many problems.

"I've always just thought doing a lot of problems is important." [I6, 236]

The instructors often expressed their belief about how students should work problems by contrasting it with what they believed to be typical student behavior.

"Students spend large numbers of hours just doing problems but not doing them with a disciplined approach.” $[\mathrm{I} 4,51]$

They were all able to elaborate their ideas about effective student practice. For example, the "disciplined approach" was a reflective approach.

"Ok, that's the way you do problems, you write equations. All right, after you've written an equation do you have a clear understanding of why you wrote that and not something else? I would call it studying with a constant focus on the principles." $[14,51]$

Instructors thought that practicing should be done on one's own, with minimal help while clarifying difficult points with peers.

"What I often say is that they have to solve problem without looking at solutions, and if they get stuck, talk to someone specifically about what the next step would be, rather than looking at solutions, so they don't get too much help, which lets them get away without actually thinking on their own." [I1, 321]

They wanted the students to do something different than merely solving problems. 


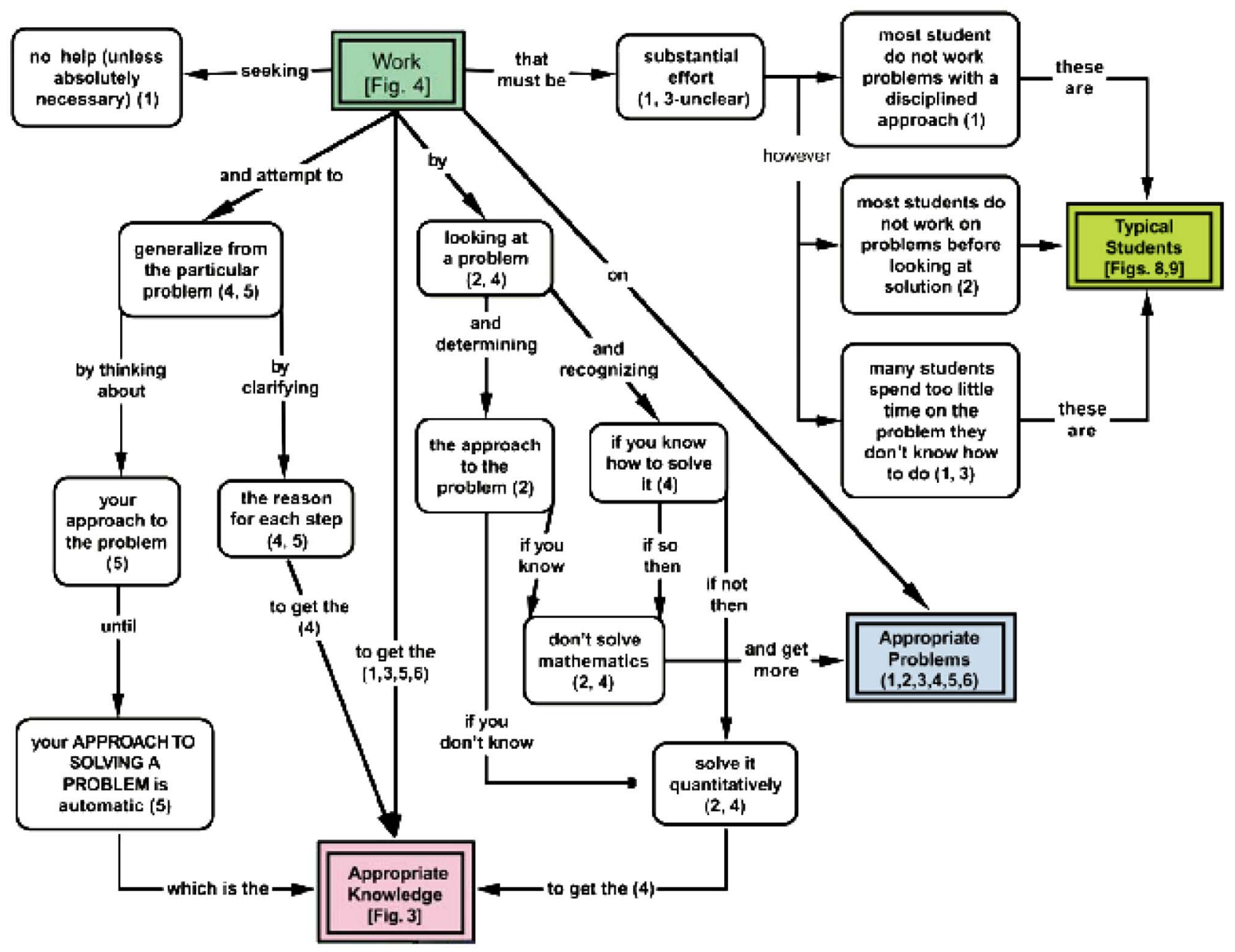

FIG. 4. (Color) "Work" composite map of faculty beliefs about learning from working problems. Numbers in the parentheses denote the instructor whose statements directly justify that category. The boxes framed with a double line indicate principal categories that are elaborated in other composite maps. Uppercase labels refer to specific types of knowledge that also occur in the "Appropriate Knowledge" composite map shown in Fig. 3.

"I often tell students that if they are having difficulty that what they should do is look at a lot of problems, not necessarily work them, but look at the problems, and then go through the strategy part of the problem saying to themselves 'what do I need to know for this problem, and what are the parameters that are specified, and what are the things that I have to calculate or that I have to know in order to solve this problem.' If the student thinks that he knows these things then he can go to the next problem. He shouldn't do the implementation and actually come to a number." $[\mathrm{I} 2,279]$

Or as another instructor phrased it, practicing should involve consciously generalizing.

"I try to get students to think consciously about their general approach. I want the students to be able to verbalize their general approach, and not just sit and wait for lightning bolts to strike." [I5, 313-314]

Four of the six instructors believed that working problems is the best way to attain the goals of the course and is also a prerequisite for learning by any other means.

"I hope that they are in the habit of looking at the homework problems and trying to do them and then when they come to class they either have already done them or they are learning something from my solving the problems and it's not just another example that I'm doing on the blackboard." [I2, 143]

In addition to reflectively working problems, most instructors believed that it was useful for students to get direct feedback and to see examples of problem solving either from lectures or from written material. The interview artifacts, student problem solution and example instructor solutions, directly prompted responses about students working problems, the utility of written examples, and students' processing of instructors' grading. However, remarks about other types of feedback and the role of lectures were spontaneous. Many of the statements on feedback centered on grading, and have been previously published. ${ }^{66}$ The composite map "Using Feedback" (Fig. 5) elaborates the instructors' beliefs about the process of feedback in student learning, whether from 


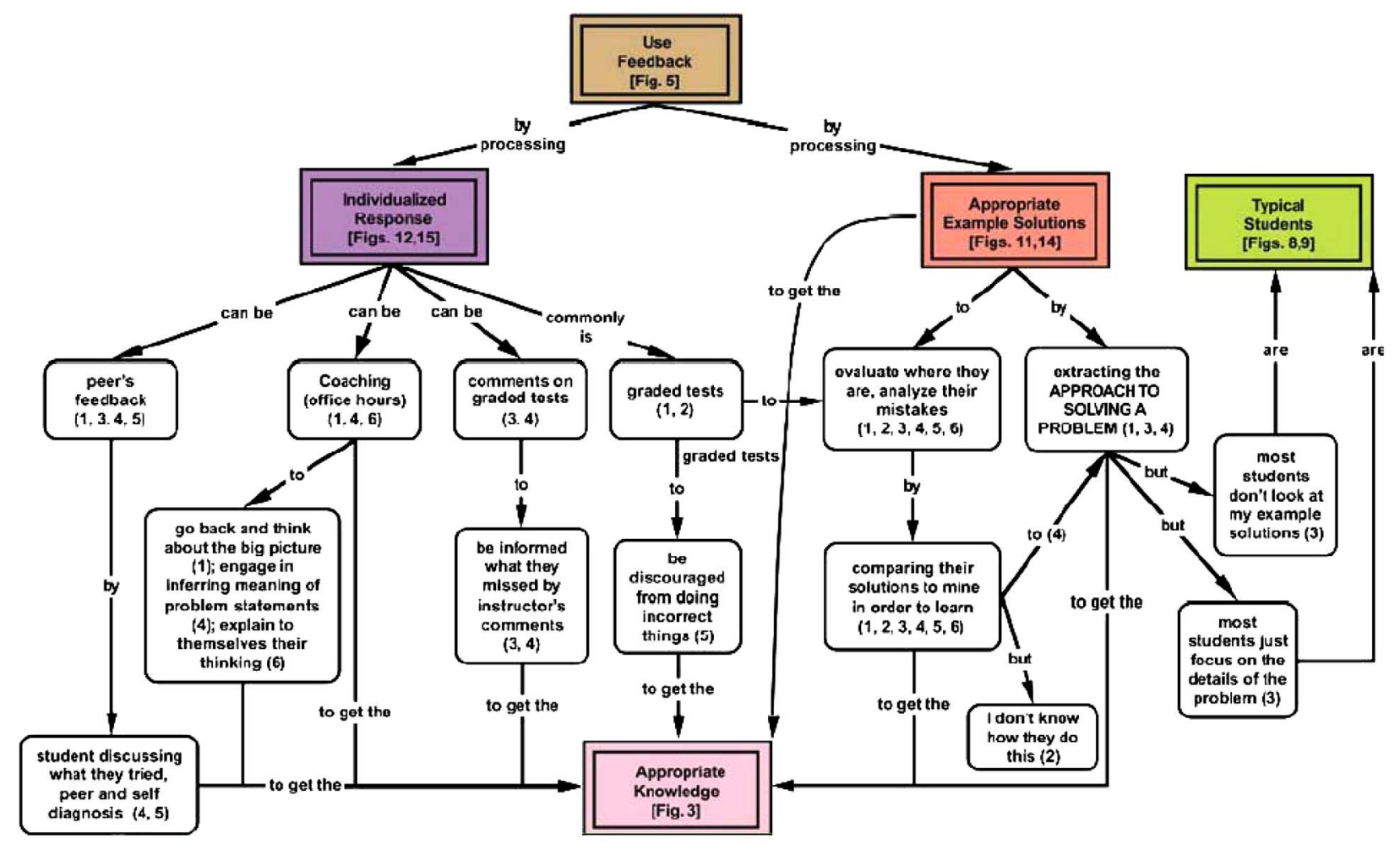

FIG. 5. (Color) "Use Feedback" composite map of faculty beliefs about learning from using feedback. Numbers in the parentheses denote the instructor whose statements directly justify that category. The boxes framed with a double line indicate principal categories that are elaborated in other composite maps.

grading and comments on students' test solutions, instructors' coaching in office hours, or from discussion with peers in study groups.

Most instructors wanted their students to compare their own work to an instructor's example solution. Some believed that students needed to go through a detailed analysis process.

"Ideally, I suppose, that students would analyze their test solution and maybe my test solution to see where the major differences are, and then try to work on it." $[\mathrm{I} 1,136]$

Other instructors seemed to believe that students could learn from just looking at the instructors' solution.

"If the students can't solve a problem, then the solution that I give them should show them how one could solve the problem, with the hope and expectation that the next time they saw something similar they would have in mind a method that they might apply to it." [I5, 30]

The instructors also believe there is a role in the learning process for instructor-generated material, such as example solutions and lectures, as represented in the composite map "Look/listen," Fig. 6. The lectures were useful to suggest to students both how they should and how they should not work on problems.

Most instructors thought students could learn from instructor solutions, without working the problem first, if they looked for an underlying structure in the solution and reflected on the solution.
"Look at a solution and get something out of it by looking at the structure of the problem, what concepts are addressed." $[\mathrm{I} 3,45]$

"Ideally, when students see my solutions, I would like them to think about what's going on. That would be my main goal, is if they can be thinking why is this step going from one step to another." [I6, 23]

Most instructors believed that learning physics happens slowly, but not incrementally in the sense of behaviorist accumulation. ${ }^{16}$

"It's a craft that students are learning. They're not learning momentum as a vector quantity that happens to be conserved. They're learning how to recognize where that particular principle comes in a problem out of the blue ... learning the craft is not a matter of doing 10 or 50 or 100 or a million problems, in particular following along somebody's scanned solution, and decide that you know the physics. The learning the craft occurs in little jumps along the way when you suddenly say, 'oh that's what this angular momentum is all about, ok, I now have mastered the idea of it." [I4, 9, $14,25]$

As with any craft, it was important that the students practice applying concepts and processes for themselves.

"They have to explore what that tool can do for you... It's important to explore for yourself what you can do with physics ideas or formulas." [I1, 105, 295] 


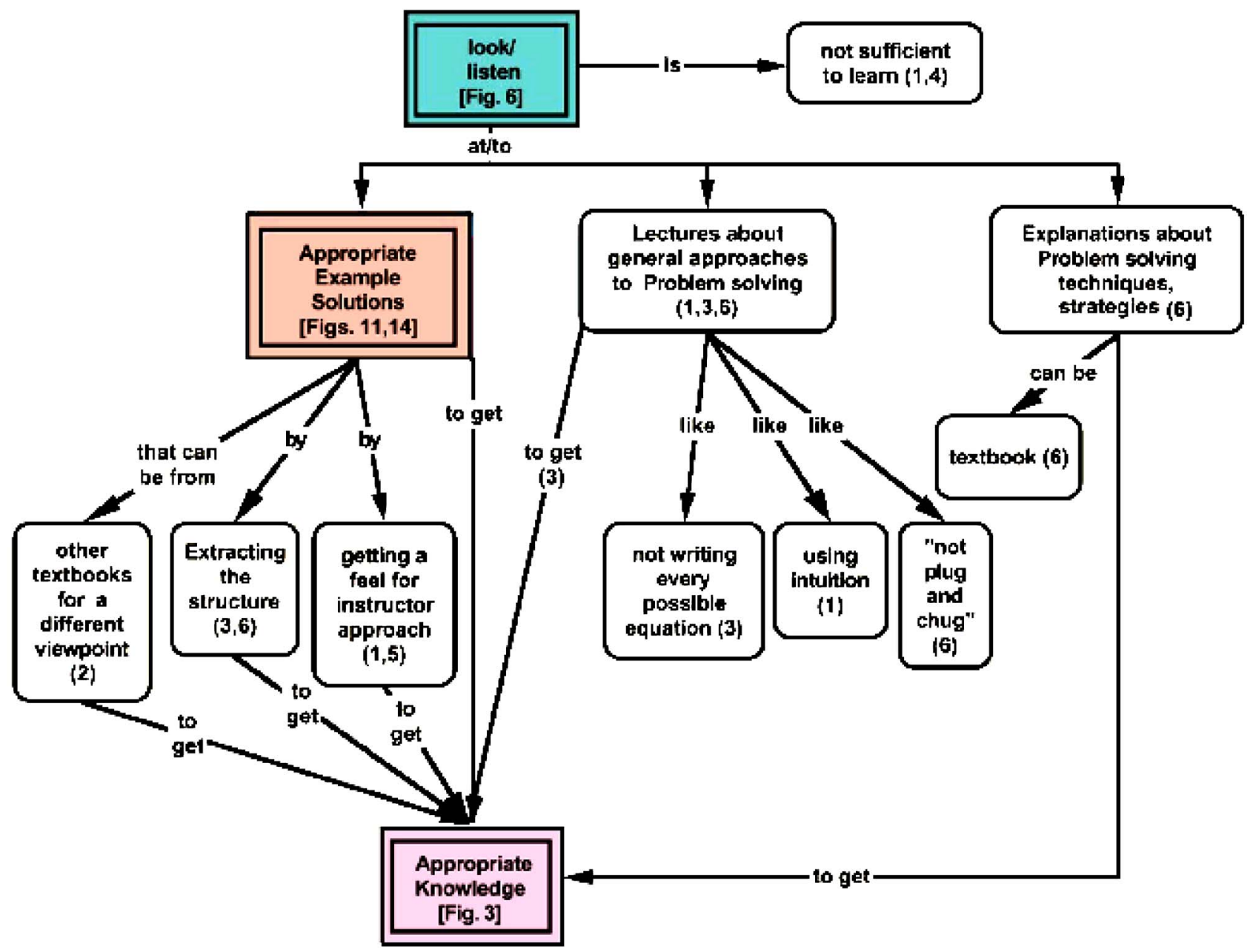

FIG. 6. (Color) "Look/Listen" composite map of faculty beliefs about learning from looking at or listening to an instructor's lecture or example problem solution. Numbers in the parentheses denote the instructor whose statements directly justify that category. The boxes framed with a double line indicate principal categories that are elaborated in other composite maps.

D. What prerequisite knowledge and skills do instructors expect of their students?

Student characteristics that instructors believed were required for success in their introductory physics course are shown in the composite map "Students Who Can Improve," Fig. 7. The prominent location of the box "Students Who Can Improve" on the main map reflects the importance the instructors gave to this issue. Early in the interview half of the instructors described, without prompting, their class composition and to which part of it they direct their teaching. This issue was also discussed in response to a question posed near the end of the interview regarding the difference between students that were able to improve and those who did not. Looking at this composite map one can see that most instructors believed the class was composed of three groups:

(1) Students who are not going to learn how to solve physics problems (15\%-33\% of the course population).

"There are people that are just not ever going to be able to do math properly." [I6, 312]

(2) Those who are so good they do not really need the course (a few percent of the course population).
"There are a few, but very few, students who can basically bullshit their way through their introductory physics, chemistry, and math classes, and basically get good grades by doing nothing." [I5, 377]

They work in an idiosyncratic way.

"They break all my rules and get away with it because they are right... and they know what they were doing." $[\mathrm{I} 3,231]$

(3) The third group of students that can learn how to solve physics problems (but do not necessarily do so).

"I think you always have to pick out the middle ones that are almost there or about there, to be able to get them over the hump." [I6, 30]

Every student in the third group was intelligent enough to succeed in the course:

"Most of the students in our calculus-based physics class are pretty bright." [I5, 391]

Yet, not all would succeed. Their success was primarily de- 


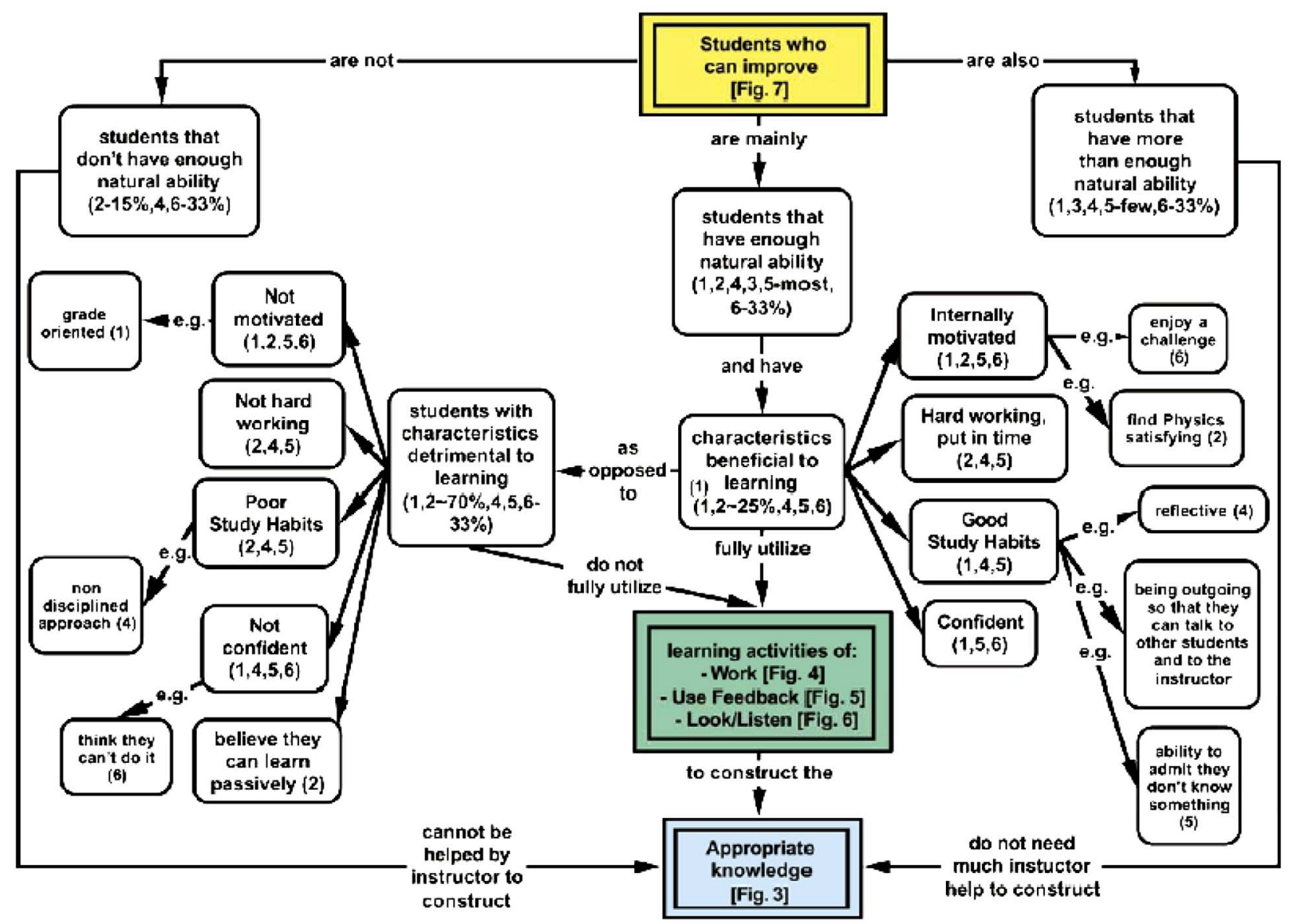

FIG. 7. (Color) "Students Who Can Improve" composite map of faculty beliefs about students who can improve meaningfully in their introductory physics course. Numbers in the parentheses denote the instructor whose statements directly justify that category. The boxes framed with a double line indicate principal categories that are elaborated in other composite maps.

termined by the following personal characteristics:

(a) Willingness to work hard on the course material. All instructors thought that this was required to succeed in the course.

"Some of the students actually collapse from the shock of actually having to put in time in college courses. That's another way they can go down... Some of it depends on how hungry they are, you know, how much are they willing to put themselves out for this." [I5, 394, 399]

(b) Caring about the course, being internally motivated.

"Interest, whether it be purely due to grades or not, can make a difference between students who are able to make improvements and students who are not" [I1, 360], "the people that enjoy a challenge." [I6, 299]

(c) Having reflective study habits.

"I think it goes back to the how you learn physics. You have to, you look at problems not to go through the problem and compare your answer with the one that's in the back of the book or up on the blackboard. But instead you have to discipline yourself to say what, why did I write this down. Exactly what was the reason why I wrote this particular line of algebra down." [I4, c419]

Using reflective study habits includes being able to interact with others.

"Being outgoing so they can talk to either their classmates or us, teaching staff." [I1, 363]

(d) Possessing beliefs about their learning as an active process in contrast to most students.

"Students come to lecture, read the newspaper, enjoy the lecture, watch the demonstrations, watch me go through the examples, and then they go and do other things for the rest of the day; until a quiz, and then in the days before a quiz they read the chapter and they think about some problems." [I2, 29]

(e) Having self-confidence.

"If they perceive themselves as not good at things, then they're not willing to spend the effort on it." $[\mathrm{I} 6,315]$

The instructors' believed that only some of the students possess these necessary characteristics because of a variety of factors:

"I wouldn't discount just the native skills and intelli- 
gence from genetics or early background." [I6, 313]

"The student who's all haggard and tired from jobs" [I4, 399]."My guess is that the students have been taught plug and chug physics in high school... We need to work on distressing things, but in some sense the best way to avoid bad habits is never to establish them in the first place." $[\mathrm{I} 3,2-3]$

"Success in education depends on previous socialization." $[\mathrm{I} 5,398]$

At no time did any of the instructors express the belief that it was their responsibility to help students develop these beneficial characteristics. At most they hope to motivate those they can.

"If I can interest $20-30 \%$ of the class... then I'm being successful." [I2, 36]

\section{E. How do instructors characterize their students' actual learning practices ?}

In all parts of the interview, the instructors described their typical students' skills, attitudes, and behavior, which were related to learning how to solve physics problems as well as to general learning. The composite map "Typical Students" has two parts: Fig. 8 presents students' knowledge and skills related to problem solving and Fig. 9 presents students' characteristics related to general learning.

Student problem-solving skills were considered from several perspectives. Their knowledge of physics concepts was described by all instructors as poor, as was their approach to solving a problem and their ability to reflect on their solution process.

"Students often do not know what things would work when solving an introductory physics problem." [I1, $33]$

"Everybody looks up formulas at some level. But relying on that as an alternative to understanding things is the problem there." [I6, 259]

"I suspect it's very difficult for students to sort of step back and be able to have the sort of oversight." [I1, 56]

The instructors thought that students believe problem solving should be quick and straightforward.

"Perhaps it's unfortunate but students kind of want the quick and dirty deal here" [I6, 51], "to get to the answer in one shot." [I1, 115]

Finally, students' communication was considered as poor because students

"don't write solutions that someone else can understand." $[\mathrm{I} 3,54]$

The description of the typical student focused on the lack of problem-solving skills or negative attitudes and behaviors.

All instructors thought that the typical student had behavior patterns that were not conducive to learning from working problems and getting feedback about problem solving.
They thought many of these students do not seriously try working a problem before looking at the solution.

"When students do homework or solve problems, it's so tempting to just look at solutions after working 2 minutes if you don't know what to do." [I1, 140]

Regarding student use of the instructor solutions they said:

"There are many students who make a mistake on the quiz and say "well that was a mistake" and then they're not interested in it anymore." $[\mathrm{I} 2,26]$

They thought even when students looked at instructor solutions they did not focus on the physics of a problem.

"Unfortunately, there is a big gap between what I would like students to do with solutions that I post and what I'm fairly sure they are doing with them... The majority of the students actually don't look at the solution that I post... A large fraction of students who do look at my solutions are focusing too much on the very problem at hand ("what is the speed or how high will it go') as opposed to the structure of the problem." [I3, 31-33, 38]

"When I do solutions on the board during class I hope that students just see how a professional thinks about these sorts of things. Of course I suspect in many cases they adopt the superficiality of it rather than thinking of the details." [I6, 20]

The instructors thought that students believe learning physics is about technical skills and easier than it is.

"Techniques is probably the only thing many of the students think there is to physics." [I1, 345]

"There are more students who think they can get good grades by doing nothing, than those who can actually do it." [I5, 379]

They considered students' motivation to be grade oriented: "Students are seeking as high a grade as possible" [I4, 123]. Most of the statements about student learning characteristics were judgmental, and the instructors were much more detailed about negative aspects of students than positive ones.

To summarize, the instructors believed that their typical student had seriously deficient problem-solving skills, general learning skills, beliefs about the goals of a physics course, and motivation. The only skills that instructors mentioned in a positive way were that some students formed study groups or were able to perform specific problem- solving techniques such as drawing free body diagrams.

Nevertheless, all of the instructors believed that the majority of their students did learn in their course. In most categories that they defined as "Appropriate Knowledge" (PHYSICS CONCEPTS, APPROACH TO SOLVING A PROBLEM, and SPECIFIC TECHNIQUES), the instructors estimated that their typical students were anywhere between "some" to "a lot" better after the course. Instructors were much less optimistic about the category of SELF EVALUATION. They expected that this type of reflection while solving a problem is something that takes more time to develop 


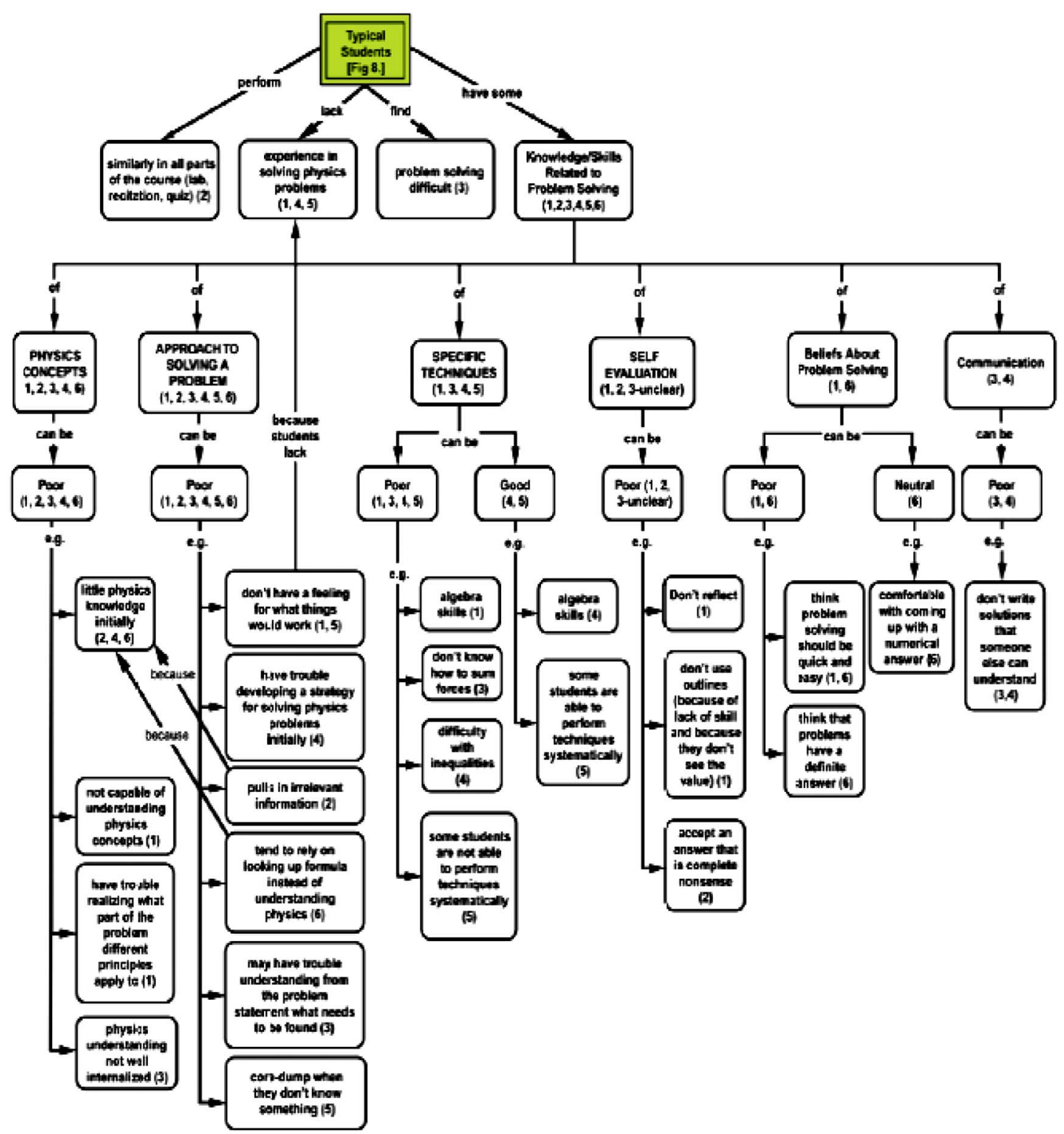

FIG. 8. (Color) Part of composite map "Typical Students" concerned with faculty beliefs about the knowledge and skills related to problem solving of typical students in their introductory physics course. Numbers in the parentheses denote the instructor whose statements directly justify that category. Uppercase labels refer to specific types of knowledge that also occur in the "Appropriate Knowledge" composite map shown in Fig. 3.

and should not be expected of students after a single yearlong class.

"The types of things in this stack (named MATURITY, containing. 'Have faith in answer', 'Recognize when something is missing', and 'Comment on result') are not built up over one course... I hope they learn some of it in the course, but it's not, these are things that aren't in the syllabus and that you hope over 4 years of a university education, that they cultivate." [I3, 373]

It is important to emphasize that this last category was comprised of skills that instructors believed would be a prerequisite for a student to learn from attempting to solve problems in the course. But at the same time, they believed that most students did not have such skills when entering their course, nor did they develop such skills in their course.

\section{F. What values underlie how instructors would prefer to design their instruction?}

When discussing the instructional artifacts, the instructors often expressed some conflict about how they believed they actually designed their instruction as opposed to how they would prefer to design their instruction in the absence of all perceived constraints. There appeared to be four different instructor values, given below, that underlie their beliefs about how they would prefer to design their instruction of introductory physics. These values appear in the composite 


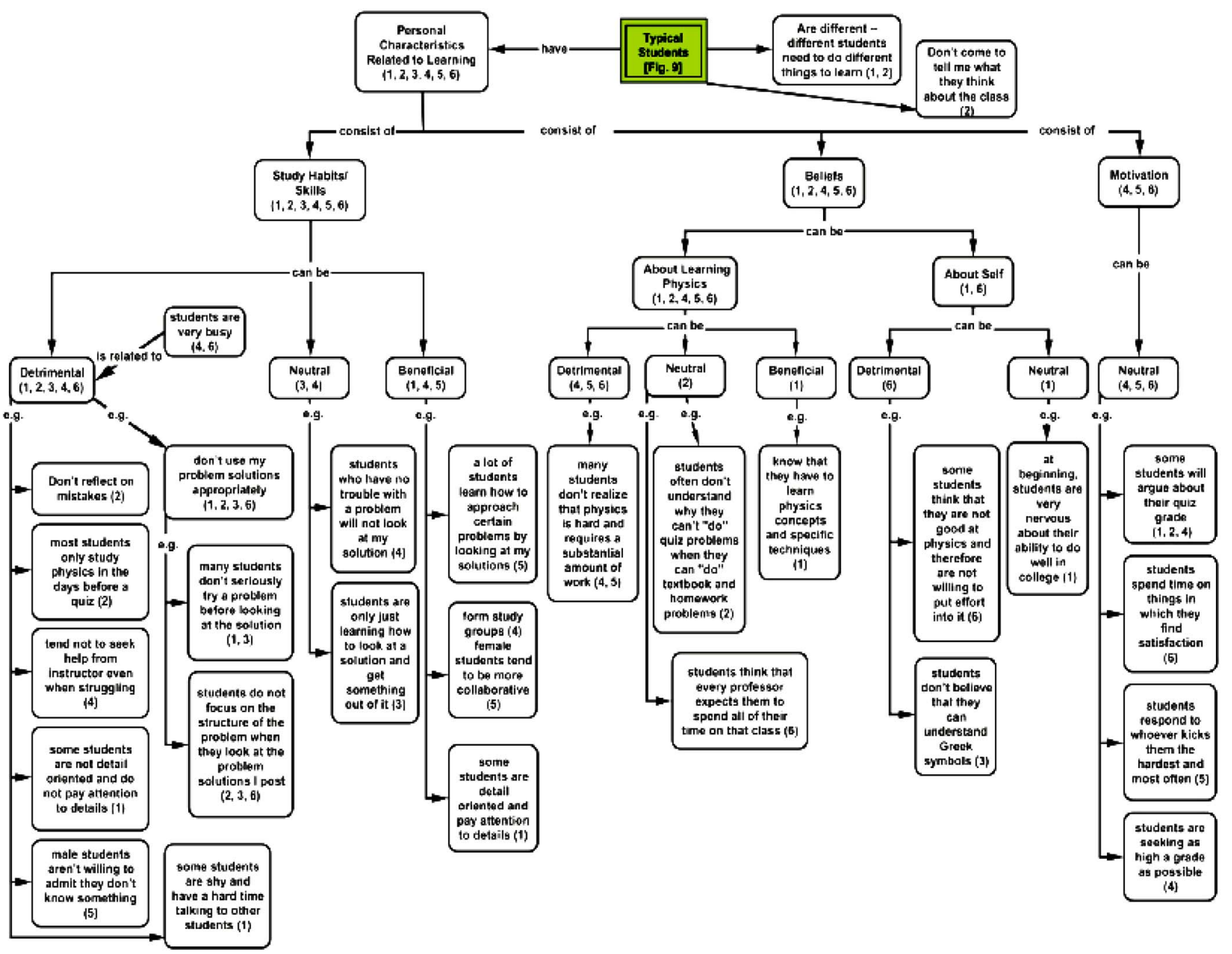

FIG. 9. (Color) Part of composite map "Typical Students" concerned with faculty beliefs about characteristics related to the general learning of typical students in their introductory physics course. Numbers in the parentheses denote the instructor whose statements directly justify that category.

maps related to instructional resources such as problems, individualized feedback, and example problems solutions. For example, Fig. 10 shows the values part of the composite map "Appropriate Problems," dealing with instructors' beliefs about the appropriate structure of problems. (The rest of this map deals with instructors' beliefs about matching problems to perceived constraints, and will be discussed in the next section.) In the same way Fig. 11 shows the values part of the composite map "Appropriate Example Solutions," and Fig. 12 shows the values part of the composite map "Individualized Responses." (See the Auxiliary Appendix of the companion paper [58] for the problem and solutions referred to in the statements below.)

\section{Value 1. Instructors value engaging students in proper} physics practice which uses correct and efficient implementation of fundamental physics concepts to solve physics problems

All the instructors thought that problems should be designed to involve students in determining which principles and concepts should be applied to solving the problem.
"So that's a nice set of questions which requires the students to think about the physics principles behind this problem." [I2, 249]

Every feature of the problem should serve to add conceptual challenge.

"I'm not sure that the context in problem $\mathrm{C}$ adds that much to the problem." [I3, 286]

Numerical grading was perceived as a tool to allow students to know what is missing in their solution, to encourage students to do the correct things in a solution, and discourage the incorrect.

"Getting graded tests or quizzes back is basically a one-line feedback to students about where they are. By looking at their test score a student gets some feedback about whether they're missing something, or it's OK, or it's a disaster, or whatever." [I1, 129, 134] 


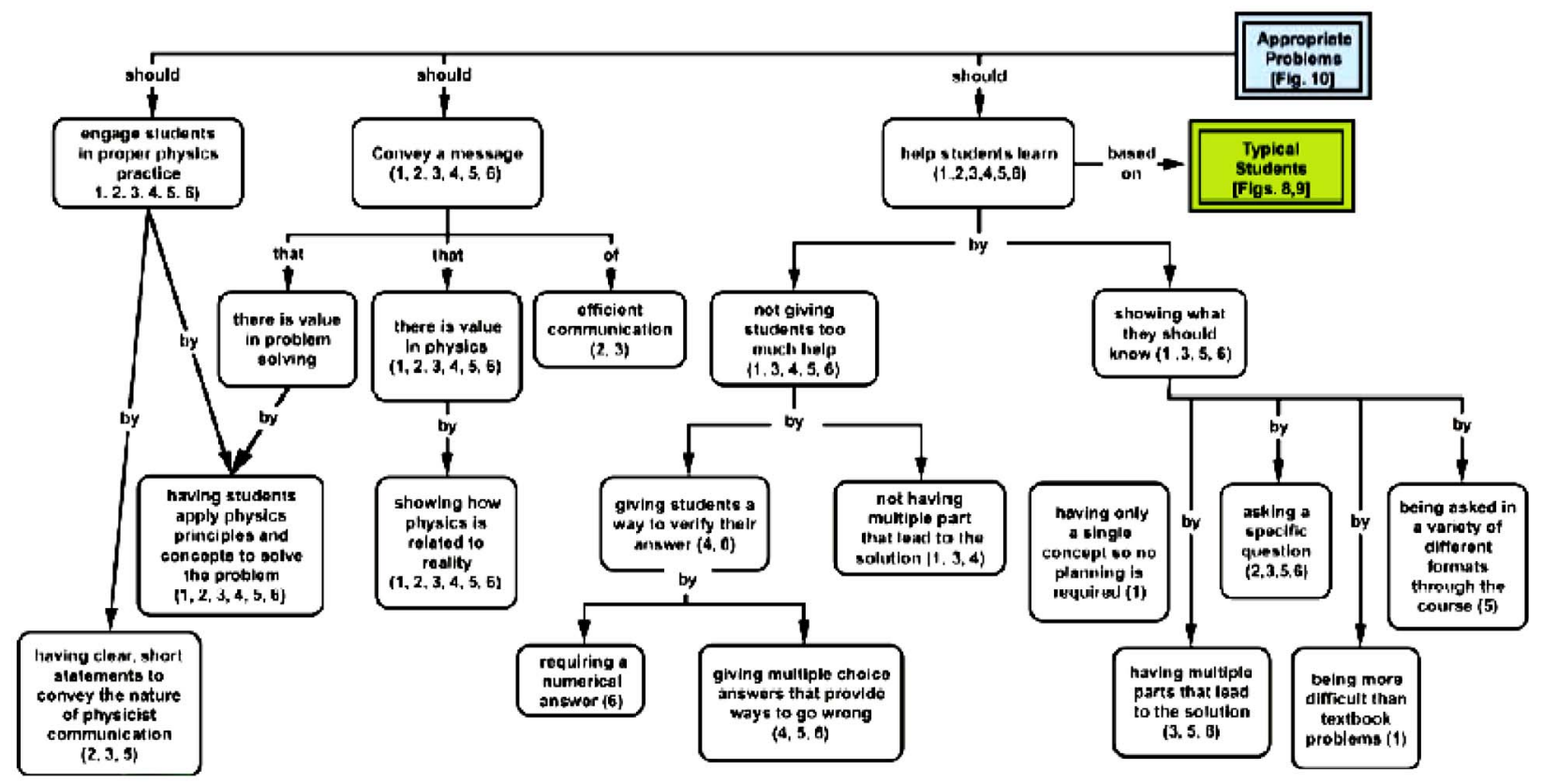

FIG. 10. (Color) Values part of composite map "Appropriate Problems" concerned with faculty beliefs about the appropriate structure of problems in their introductory physics course. Numbers in the parentheses denote the instructor whose statements directly justify that category. The boxes framed with a double line indicate principal categories that are elaborated in other composite maps.

Three instructors thought their example solutions should be in a form that an expert physicist would write when doing physics.

"I post Instructor Solutions to demonstrate what a professional physicist strategy for the problem solving would be." [I6, 12]

It should be an effective solution-the shortest path to arrive at the result.

"Instructor Solution 2 [is poor because it] goes through step by step instead of simply writing down the important parameters." $[\mathrm{I} 2,51,76]$

It should not give the implicit thought process, and it should avoid giving generalizations or pointing out possible complications for the sake of being compact.

"When I am solving a problem I don't say to myself out loud or even quietly all of the explicit things ('that first I need to find this, then I need to do that') as Instructor Solution 2 does." [I2, 54-5]

"The possibility of a lot of complications is allowed in Instructor Solution 2 and they're tossed out. A more expert solution (like Instructor Solution 1) doesn't even mention that term in the first place... I'd prefer to see a problem solving approach in an instructor solution that more artfully tailors the solution to that particular problem rather than having some more general approach." [I4, 48, 58]
2. Value 2. Instructors value conveying the message of the beauty of physics and the satisfaction they find in it, which requires clear communication, relevance to reality, freedom of thought, and ego fulfillment

Instructors' appreciation of the clear and efficient style of communication of physicists was reflected in statements about how they design problems.

"I think we should be as clear in stating a test problem as I think my graduate students should be when talking to me about what they are working on." [I3, 295]

"I don't like problem B because it is awfully wordy." [I2, 238]

They wanted to include realistic context in a problem to convey a message that physics is real and relevant, and they rejected problem contexts that they did not believe could actually take place.

"Problem A will give them the impression that physics is completely isolated from real life." [ $[\mathrm{I} 1,254]$

"Context rich problems are better if they really correspond to some situation that's real, that's really real rather than sort of a contrived situation." [I4, 308]

"Problem $\mathrm{C}$ is not really real life because, in reality, nobody is going to throw a bag of nails up on a roof by twirling it on the end of a string. Most people are going to use a hoist or a man-lift, or something like that...A real-life problem must have situations where, for example, architects and structural engineers would actually deal with." $[\mathrm{I} 5,245,250]$ 


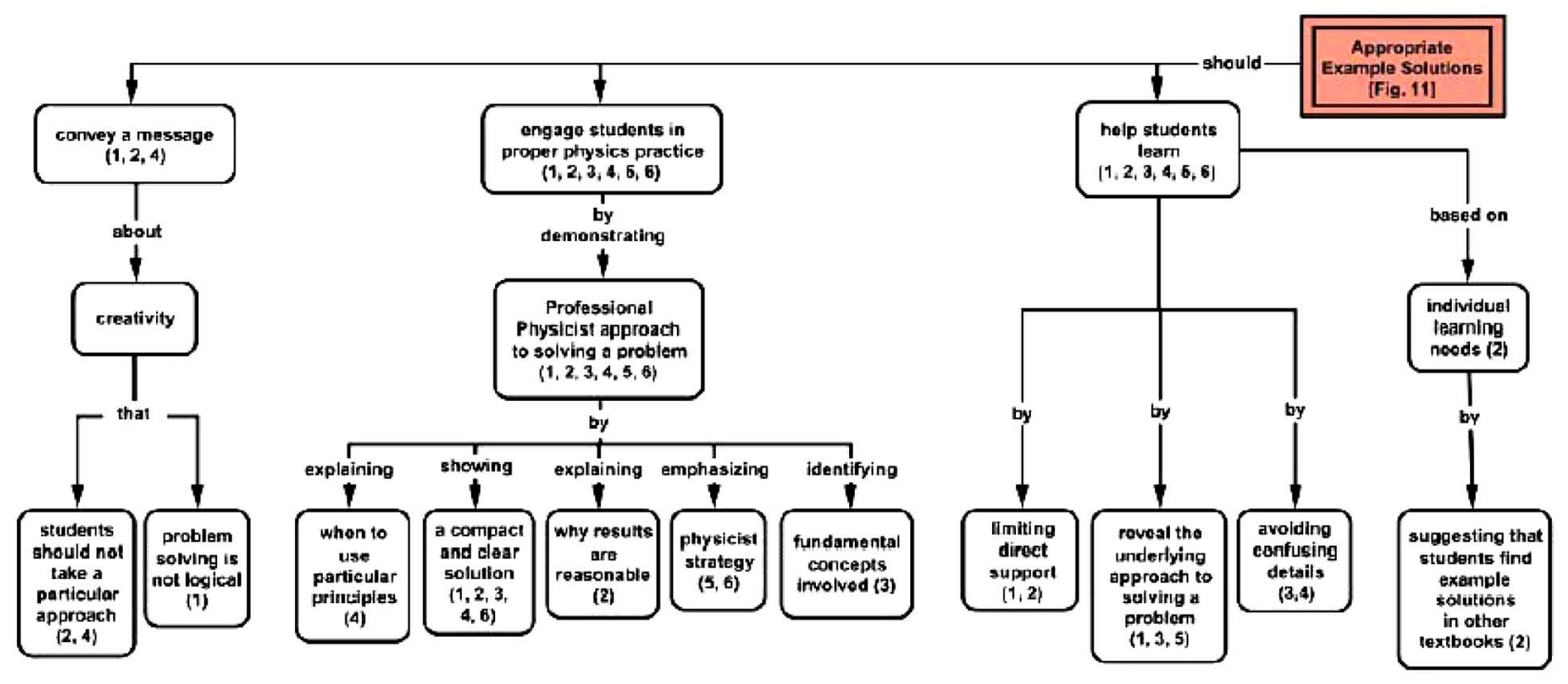

FIG. 11. (Color) Values part of composite map "Appropriate Example Solutions" concerned with faculty beliefs about the appropriate structure of example solutions in their introductory physics course. Numbers in the parentheses denote the instructor whose statements directly justify that category.

They thought that instructor example solutions should emphasize the message of individual creativity.

"To say to the student 'Oh, but you have to go through these individual steps which are implicit in the solution that you 've already gotten,' that 'it doesn't count,' or that 'we want you to approach this solution by analyzing each step, and then assembling those steps into a final solution,' that is asking the student to take a particular approach to solving the problem." [I2, 79]

"I think having a lot of writing (like Instructor Solution 2) has the effect of saying 'I want to have a kind of a standard way to do 2-dimensional motion problems...Solving physics problems is kind of an art, It's not exactly something that you just follow some set path and crunch your way through to a solution." [I4, 51 56-7]

Finally, instructors wanted to make sure numerical grading provided ego gratification to the good student. The instructors raised this issue when they discussed Student Solution E (a very sparse solution with a correct final answer) because their inclination was to violate their grading policy of requiring justification of the final result. ${ }^{66}$ [The student artifacts can be found in the companion paper (Ref. 58).]

"Yeah, I do have the policy that students have to explain their work." [I4, 171]

They recognized that Student Solution E is missing reasoning.

"Student Solution E certainly doesn't give you much in the way of explanation for the solution." [I6, 102]

Yet, they decided to ignore it.

"There is a switch that I turn on when I'm dealing with a student (like Student Solution E) who I think knows what's going on." [I3, 228]

The reason to change policy was that taking off points might discourage able students.

"I would want to see Student Solution E not discouraged by grading them harshly even if you had the policy of, display your work, because, it's a student expert in my opinion." [14, 170]

"This sounds very elitist, but letting the good students know that they're good at physics ...." [I3, 405]

Most of the instructors could not believe that the student who wrote Solution E could have made the same physics errors as the student who wrote Solution D, even though the two solutions were identical except that student D wrote explanations while student $\mathrm{E}$ did not.

\section{Value 3. Instructors value helping student learn by presenting students explicitly with what they should know}

Instructors value presenting students with all that they need to know to determine the answer to a problem. This value is reflected in three instructional actions: (1) supplying problems broken down into small subparts so that students are led to solve the problem efficiently; (2) modeling how a student, who did not know how to solve a problem could approach it and then communicate the solution; and (3) providing the students with a diagnosis of the nature of deficiencies in their solutions.

Several instructors were aware that the artifact Problem A walks the student through the solution process, in comparison to the version of the problem they received ahead of the interview as "homework."

"Instead of throwing the students a compound problem written in a way like the 1homework' and expect them to be able to divide it into parts, alternatively, you can present the same problem already divided into parts 


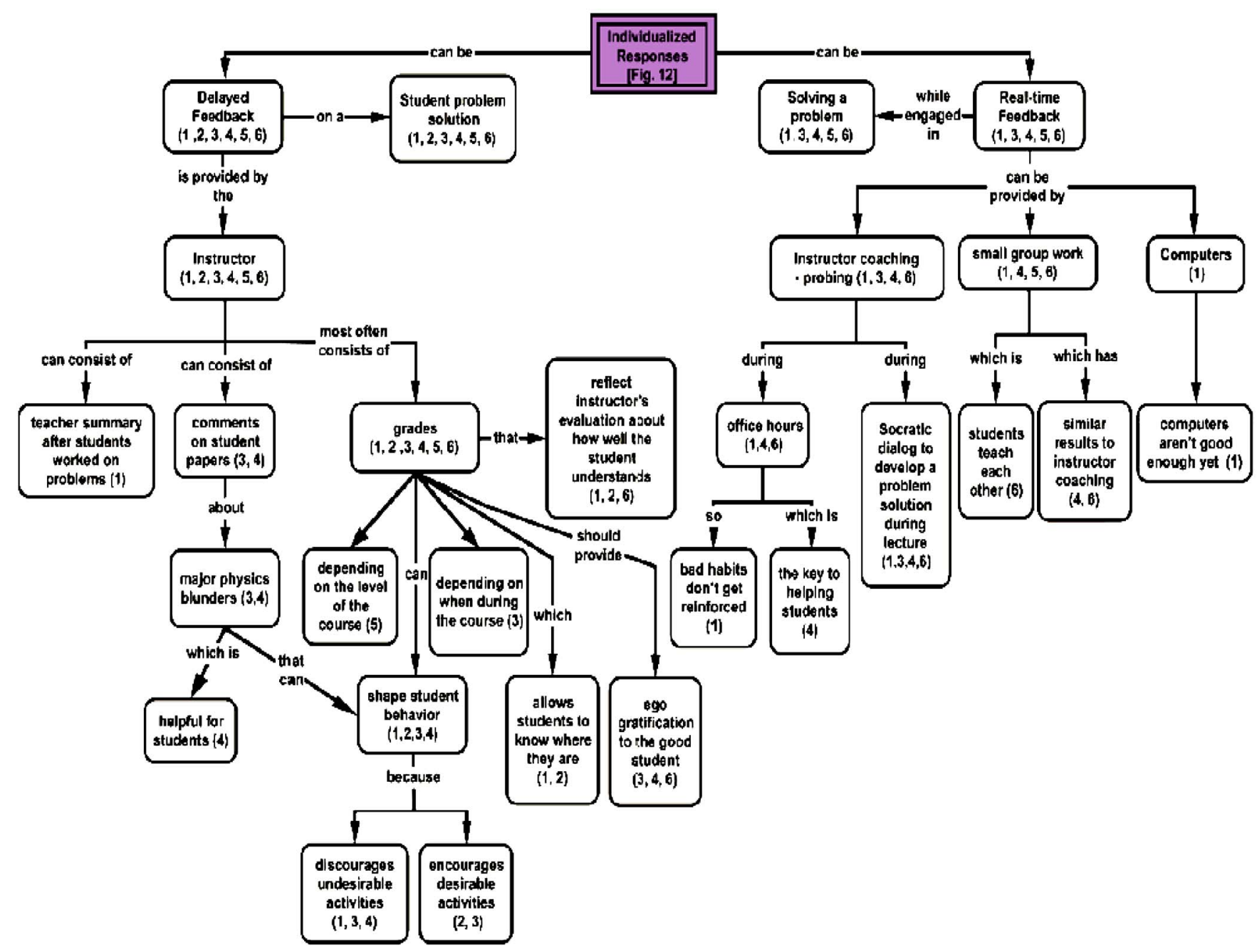

FIG. 12. (Color) Values part of composite map "Individualized Response" concerned with faculty beliefs about the appropriate structure of individualized response in their introductory physics course. Numbers in the parentheses denote the instructor whose statements directly justify that category.

and attempt to lead the students through it." [I5, 218]

Some thought it is a good thing.

"You're giving students a chance to show that they know kinematics and then that they know energy conservation and then finally that they know about rotational dynamics." [I3, 319]

"It does guide students to doing it the right way." [I6, $174]$

Others disliked Problem A, either because guiding the student does not respect their individual freedom of thought, or because it does not guide them the right way.

"Problem A leads the students in the wrong direction at first, which I think is perverse." $[\mathrm{I} 5,263]$

The instructors believed that modeling a solution should reveal the underlying approach to solving a problem. The student should get the nature of the problem-solving process, either the linear nature or the exploratory nature, depending on the instructor's view of the problem-solving process.
"The strategic things that students should get out of instructor solution's include the ability to translate the problem into a physical diagram of the situation, identify exactly what's being asked, identify what fundamental physics concepts are going to be used to solve the problem, and to determine a sophisticated and disciplined path to solve the problem." $[\mathrm{I} 3,50]$

"In my instructor solution I try to emphasize when the solution is not logical and when I guessed and used trial and error by saying that 'I noticed that this relation might work.'" [I1, 31]

Finally, instructors valued explaining to students where they went wrong.

"Obviously if you find that there's just some misperception displayed in some student's solution to a problem, if the grader can say, 'does not apply here because...' or something like that, it's certainly very useful to the student." [I4, 132]

Even numerical grading was perceived as a tool to show 
students what thought processes are missing from their solution, to encourage appropriate approaches, and to discourage the inappropriate ones.

"I tend to look at grading a test as almost an essay rather than multiple choice. I want to see the reasoning." $[\mathrm{I} 6,79]$

"I do try and design my grading, my feedback mechanisms, to specifically discourage things that I think are very bad habits, for example not awarding partial credit in cases where a solution paper sort of carpet bombed the formulas." $[\mathrm{I} 3,370]$

"I have told my TA's that if the student writes something indicating PERSPECTIVE that they should get credit for it." [I2, 293]

\section{Value 4. Instructors value helping students learn by having students find their own path to a solution}

Several instructors stated that they designed problems to challenge students and have them explore the possible solutions. For this reason, one instructor believed he should not break down problems into smaller subproblems.

"I stopped using problems like Problem A because they give too many hints, which I want students to be able to figure out on their own." [I3, 252]

Several thought they should pose conceptual challenges to their students.

"These (parts of Problem D) are great with the acceleration. Students are going to be scratching their heads for a while.” $[13,337]$

Several instructors hoped students would reflect on their solution by requiring them to verify their answers, for example by multiple-choice problems.

"If you had definite answers (as in Problem B) it might make you check back your answer." [I6, 223]

One instructor insisted that in his example solution he would not show the underlying reasoning as it denies students the opportunity to figure things out by themselves.

"With an instructor solution like Instructor Solution 1, some students will do a lot of figuring out. That process is probably useful." [I1, 80]

All instructors believed that learning takes place when students explicitly employ metacognitive processes while solving problems and that they could guide students to do this.

"I guess coaching them to always go back to the big picture technique (Where are you? Have you figured out all the physics parts? Have you understood the English? Have you understood the physics?) would help students in this area." [I1, 318]

Four instructors explained how they would guide a student to reflect on their problem solving by limiting direct support while probing the student.
"When a student gets too much help when solving problems they get away without actually thinking on their own." [I1, 322]

"I almost never give straight problem solutions during lecture-I have students list the target quantities, list the so-called known quantities, and what kinds of relations they think they can use to relate them." [I1, 38]

Most often guiding students in this way was in the context of coaching a student in their office.

"When you send a student to the blackboard and quiz them, in the worst case, they're going to say, 'I haven't any idea what to do in this problem, I'm just absolutely in the dark.' So you say, 'All right, let's start'... What do you think happens? Draw a picture of what you think happens." [I4, 329]

"I kind of try to probe, well, what are you thinking." $[\mathrm{I} 6,245]$

The instructors tend to call this mode of teaching "Socratic dialogue" [ $[\mathrm{I} 3,43]$. Four instructors mentioned group work as a venue to encourage students to reflect on their problem solving.

"I think mixed gender study groups are more effective in helping students learn because, particularly first year male students, half of them are not capable of studying in all-male groups and getting an optimal return out of that, because they're too much into not admitting that they don't know something." [I5, 385]

In summary, values 1 and 2 (engaging students in proper physics practice and conveying the message of the attractiveness of physics) seem to reflect the faculty perception of the physics culture because they focus on how physicists solve problems and what they enjoy when practicing physics. Values 3 and 4 (helping students learn by explicit guidance or by having students find their own path) seem to reflect the faculty perception of a teaching culture because they focus on how a teacher mediates the subject matter to the student. Values 3 and 4 imply two contradictory learning/teaching models. The first is transmitting: providing an explicit path for the student lacking that knowledge. The second is extreme constructivist: setting goals without limiting student options. The same instructors expressed these different and sometimes conflicting values in different parts of the interview. No instructor explained how they might integrate these values or seemed aware of the conflicts.

\section{G. What instructors believe limits their instruction}

As mentioned earlier, all of the instructors believed that at least three constraints caused them to compromise their instruction: (1) their workload and that of their teaching assistants, (2) students' expectations and preferences, and (3) their limited professional knowledge. These constraints appear in the composite maps related to the instructional resources. Figure 13 shows the constraints part of the "Appropriate Problems" map (completing the partial map of Fig. 10). Figure 14 shows the constraints part of the "Appropriate Ex- 


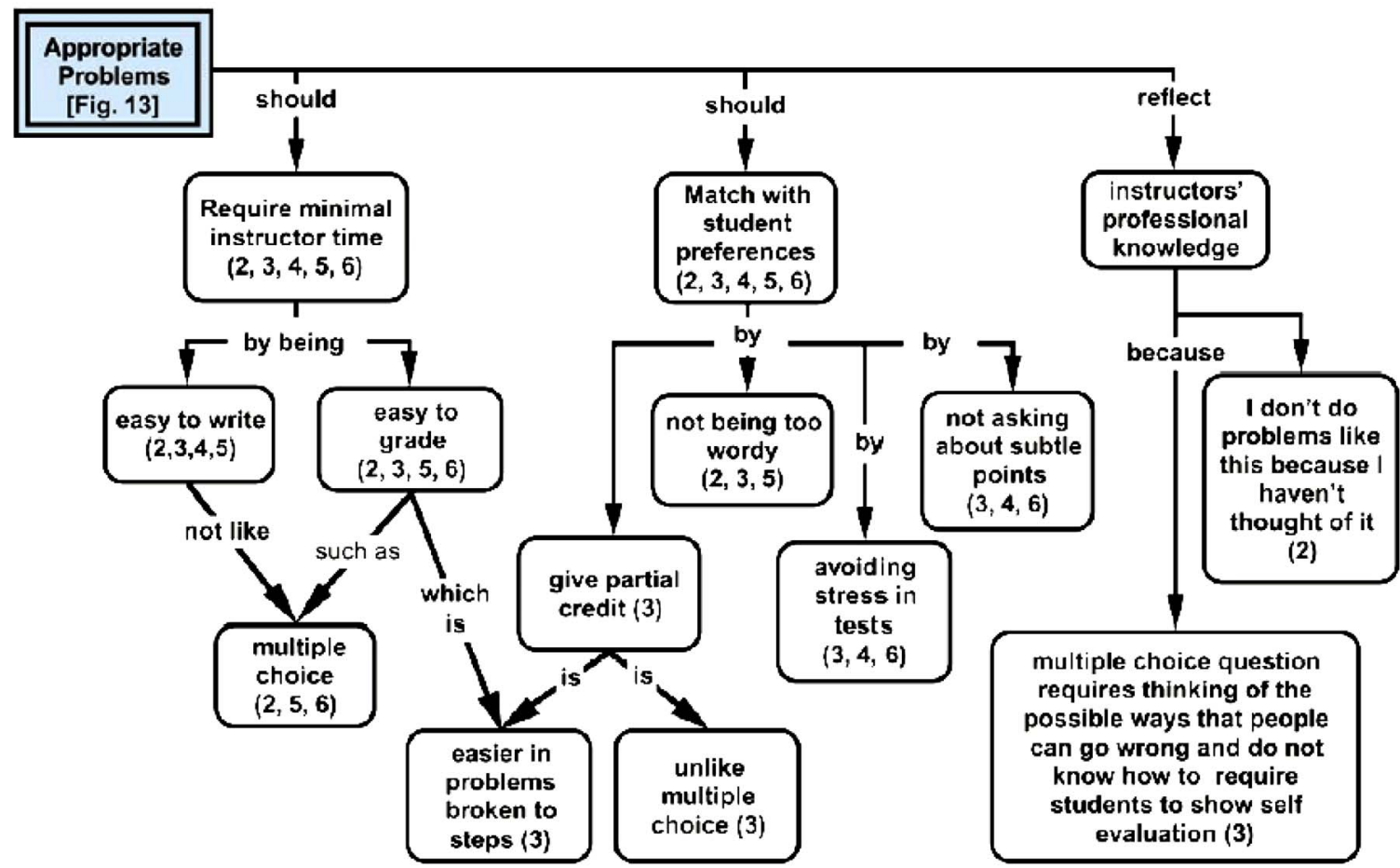

FIG. 13. (Color) Constraints part of composite map "Appropriate Problems" concerned with faculty beliefs about the appropriate structure of problems in their introductory physics course. Numbers in the parentheses denote the instructor whose statements directly justify that category.

ample Solutions" map (completing the partial map of Fig. 11). Figure 15 shows the constraints part of the "Individualized Responses" map (completing the partial map of Fig. 12).

\section{Constraint 1. Workload}

The limited time instructors could afford to put into their courses affected how they designed both the tasks and the feedback for their students. Half said that they give multiplechoice problems mainly to make grading easier.

"I use multiple choice questions (like Problem B) partly to go easy on the TA's." [I2, 236]

Four instructors believed that writing problems that focus on qualitative features requires too much time.

"It would be, yeah, I would do stuff like this (Problem

D) to the extent that I have time to do the graphics.

This is labor intensive." [I4, 300]

All instructors thought that instructor solutions should require a minimum amount of instructor time.

"If I can find a solution worked out, then I can scan it and put it on the web. To do more than that, more complex solutions, would take much longer, and I don't have the time, so I use solutions like instructor solution 1." [I5, 44, 46]

Instructors recognized they do not provide as many diagnostic comments as they favored.

"Making useful comments on the quiz solutions is la- bor intensive, and we're always kind of short of man or person-hours to do everything that needs to be done with the elementary teaching." [I4, 130]

They also recognized that they can do very little coaching.

"Well it's, obviously in a big lecture it's impossible to do." [I1, 326]

"I think engaging students and getting them to do something, no matter how wrong it might be, getting to do something on their own while you help them is, I think, the key. It's labor intensive though." [I4, 339]

They thought that even the limited time they can provide is not appropriately used by students.

"One thing I was disappointed with in that course, and in others, is figuring out ways of getting students involved with coming to office hours and things like that." [I6, 338]

When considering time constraints, the instructors focused on their time outside of the classroom used to prepare resources, grade, or coach. Shortage of time in the classroom to "cover the material," often expressed by faculty, ${ }^{67,68} \mathrm{did}$ not arise as a constraint in any interview.

\section{Constraint 2. Students' expectations}

This constraint had three manifestations. The first is not requiring actions that instructors believe add too much stress to the student. 


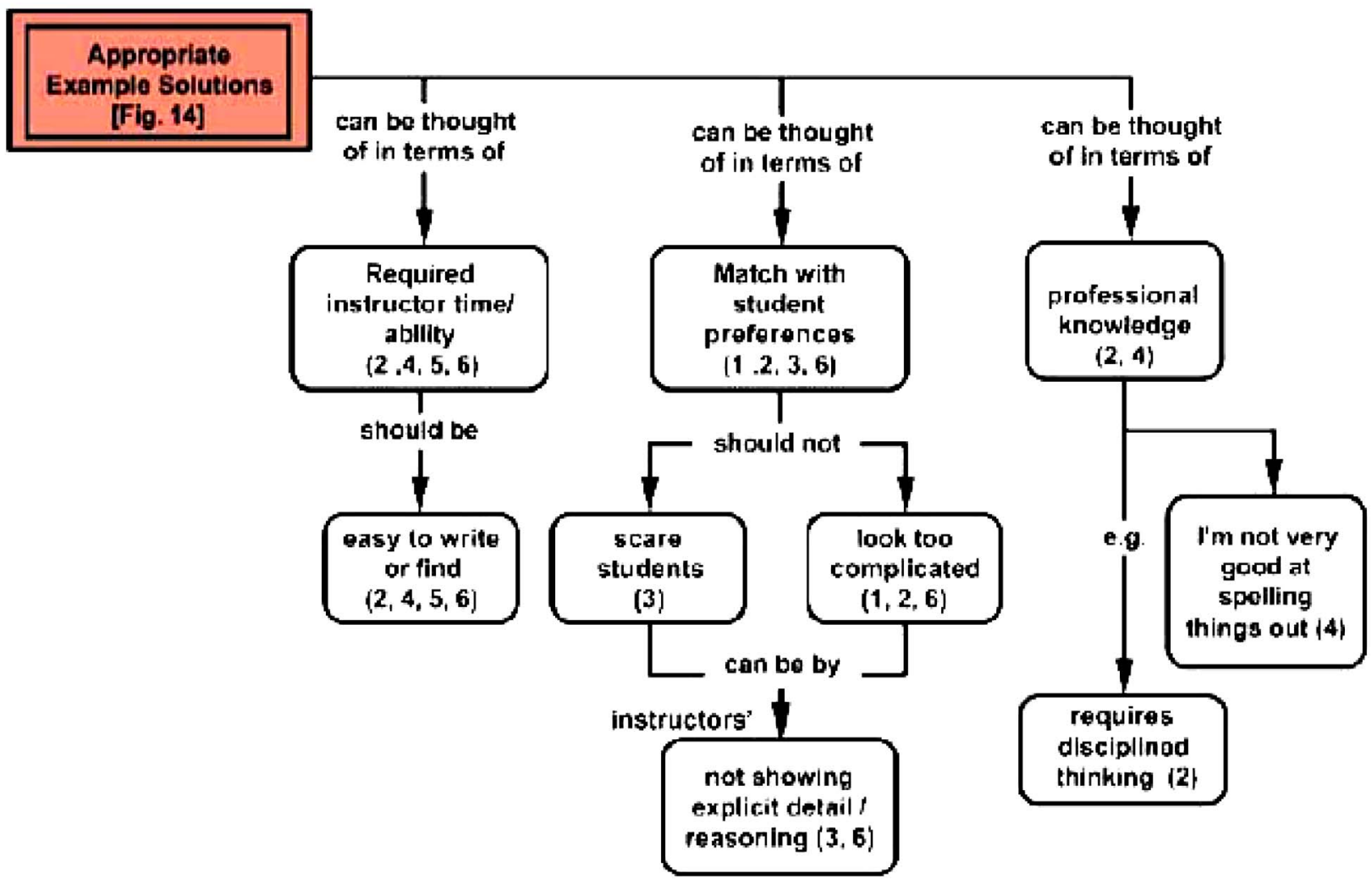

FIG. 14. (Color) Constraints part of composite map "Appropriate Example Solutions" concerned with faculty beliefs about the appropriate structure of example solutions in their introductory physics course. Numbers in the parentheses denote the instructor whose statements directly justify that category.

"I don't like it (Problem C) as a test problem in a high-pressure situation." [I3, 284]

"Now let's see. Is Problem A stated in such a way that it gives an easy analysis?" [I4, 269]

All instructors thought that instructor solutions should not be too long or complicated in order not to repel students.

"There is a class of students who will get this problem, walk right through it, without worrying about this point. So they might be thrown a little by putting this description [of possible approaches] in the middle of Instructor Solution 3." [I3, 119]

"Explicit details-is I think it kind of turns students off in some ways... You look at Instructor Solution 1 and say 'oh, that's a nice easy problem' and you look at Instructor Solution 2 and say 'oh gosh, this is really complicated.' " [I6, 52, 54]

The final students' expectation constraint was avoiding a confrontation with students, especially the good students.

"If I had graded this not very well and the student came back to me and says, 'but I got it right,' that's what I would tell them, is that you didn't really show that you're doing the right principles... I would tend more to give them the benefit of the doubt when grading a quiz solution." [I6, 133, 143]

\section{Constraint 3. Professional knowledge}

Instructors recognized that certain instructional actions require them to think about students' difficulties in a way that is not natural for them.

"If I were preparing a solution sheet and posting a solution sheet, my tendency would be to simply post this (Instructor Solution 1), because I don't anymore discipline myself to say that a problem solution has to be done in the various steps that are implicit in IS (Instructor Solution) 2." [I2, 68]

"It takes a lot of work to write a multiple choice question. In this case you have to go through the possible ways that people can go wrong." [I3, 277]

"Even though I like Instructor Solution 3 I'm likely to produce something like Instructor Solution 1 because I'm not very good at spelling things out in this way. I have a tendency to race ahead because I see my way through to the end." [I4, 93]

One instructor recognized that he lacks the knowledge for constructing problems that will cause student solutions allowing him to provide feedback on issues he deems important.

“... providing positive feedback to encourage the types of things... There's nothing specifically that we test for 


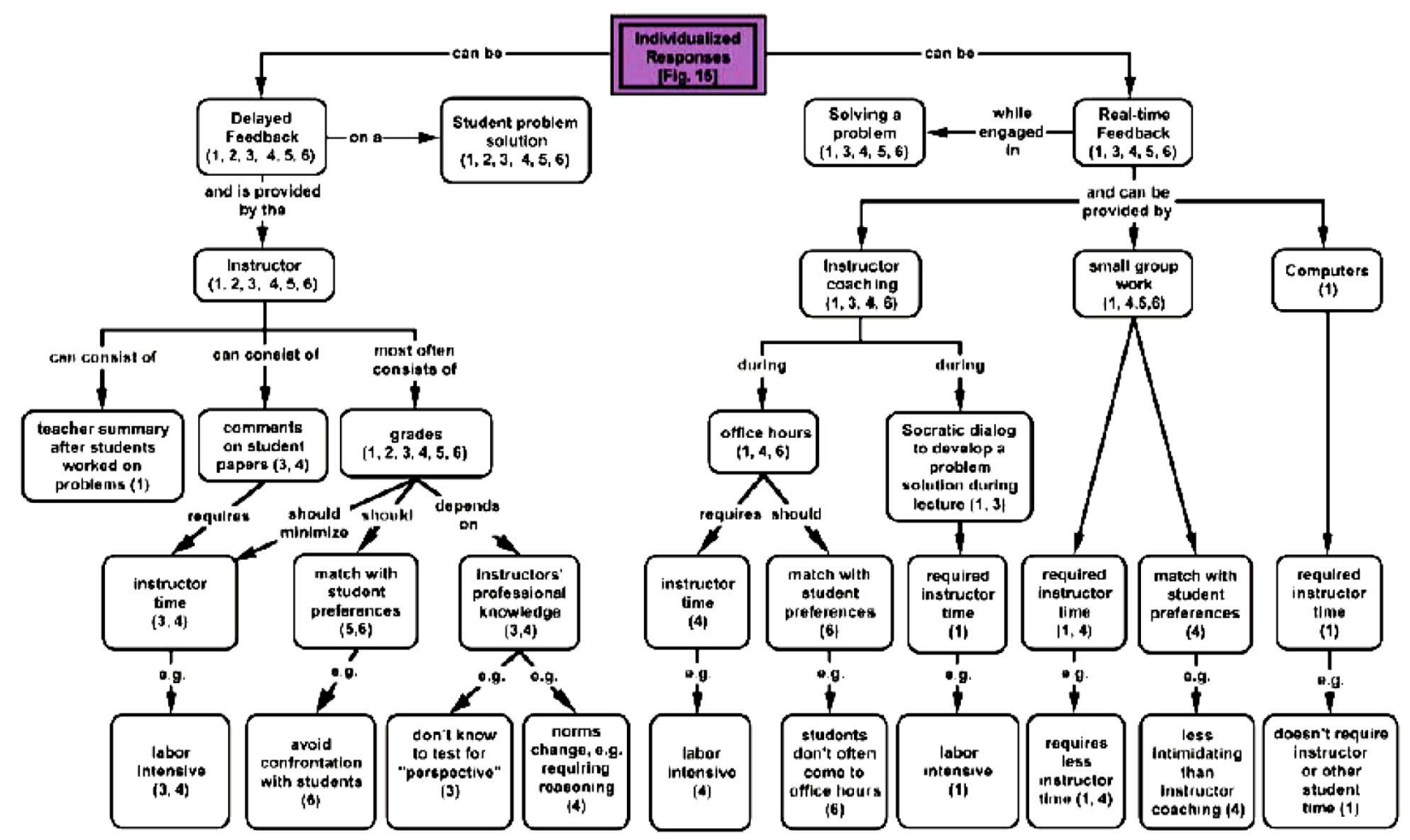

FIG. 15. (Color) Constraints part of composite map "Individualized response" concerned with faculty beliefs about the appropriate structure of individualized response in their introductory physics course. Numbers in the parentheses denote the instructor whose statements directly justify that category.

that really brings these things out." [I3, 372]

Another instructor noted how norms change and with them instructors' awareness of the need to communicate reasoning.

"Now, if we were doing this the way we, you know, I think everybody is making more of an emphasis about explaining your work, we do that a good deal more. Years back we didn't. We said, ok, answer. So by the old method of grading Student Solution E would be a 10. No problem." [I4, 168-9]

Because these perceived limiting factors often conflict with an instructor's values, their instructional preferences reflect how they resolve this internal conflict.

\section{H. How do instructors weigh their values, perceived constraints, and beliefs about students to arrive at their instructional preferences?}

The instructors often expressed that they were conflicted about their instruction.

"In the ideal world you would use problem solutions and grading of them far more for teaching than for stratifying the student population. But I think the real situation here, and probably it's typical, is that you just don't have the time for it." [I4, 133]

When faced with internal conflicts between values reflecting the physicist culture (values 1 and 2) and values reflect- ing the teaching culture (values 3 and 4), the instructors' preferences tend to align most closely with the physicist culture. For example, instructors described their problem solutions, both in the classroom and as posted solutions, as being similar to Instructor Solution 1. This solution presents a compact path to arrive at a correct result, reflecting the concise communication physicists appreciate. They did not believe they should provide detailed solutions because of their belief that such solutions limit the students' intellectual freedom of having their own solution style.

Those instructors who favored giving solutions that detailed the underlying thought process felt constrained not to do so because of lack of time or lack of knowledge of how to do so. They recognize that students have difficulty understanding their short expert solutions.

"A student who was not able to do the problem might find an instructor solution that is just symbols equally foggy, equally unclear." [I2, 73]

However their response is to supplement their actions in a manner which is not totally satisfactory to them.

"What I do when a student comes to me and says 'I'm having trouble' is to give him another textbook... Which for many students is enough, but for some students, it doesn't turn out to be enough, or for some students it doesn't speak to the way they think." $[\mathrm{I} 2,298]$

The problems instructors described assigning their students tended to be stripped to the essential physics and effi- 
ciently communicated. A minimal context was often used to communicate their value of physics representing reality, but the context was perceived as being stressful to the student. Many features of instructional design that were believed to be useful were not used because the instructors perceived them as not being necessary components of physics knowledge. For example, although they believed having a problem context raises student motivation and reflects the instructor's value of connecting physics to reality, they chose not to provide problem contexts. Instructors perceived adding context to problems as assessing language skills, which they did not see as appropriate.

"I feel very reluctant to put anyone in a situation where their ability to parse an English sentence has a significant impact on their grade." [I3, 302]

Instructors also believed that effective learning of physics using problem solving required students to construct their own solution path to a realistic problem. However, they had difficulty conceiving how to assess such student action when it did not result in a correct answer or how to give feedback to encourage it. Their resolution was to give such problems in nongraded situations.

"Maybe more for a homework problem that would be all right or for a group problem in a discussion section for example." [I6, 187]

Their feedback on students' work consisted primarily of numerical grading that penalized clearly incorrect statements. ${ }^{66}$ Instructors took special care in grading to bolster the self-esteem of the students they judged as good. Feedback about reasoning was valued only for those students they judged as poor, although few expressed the ability to do this due to time constraints. Coaching students was primarily discussed with respect to their individual actions with the few students who came to their office hours. Some mentioned the value of peer coaching of students working in groups. However, even though all instructors had many teaching assistants whose primary function was to coach students, none mentioned managing this TA resource as a way of giving guidance to the students.

When matching their conflicting teacher values to their preferred actions, the result appeared to be an unstable set of instructional beliefs. Sometimes the dominating value was the desire to offer the students guidance (Value 3), while sometimes the desire was to have students figure things out on their own (Value 4). For example, several of the instructors were reluctant to write detailed student solutions that would limit the student creativity that they valued, but favored breaking down a problem into parts to force a student along an effective solution path.

A possible explanation for why instructors tended to give their physicist values added weight is that they believed that perceived constraints favor their physicist values. Their physicist values are aligned to student expectations even when they are not aligned with student needs, and tend to minimize the perceived workload on the instructor and the student and avoid professional skills that instructors believe they lack.

\section{CONCLUSIONS}

The most important conclusion of this study is that it appears to be possible to build a model of common faculty beliefs and values with respect to the teaching and learning of problem solving in introductory physics. The physics faculty that we interviewed appeared to have a limited and classifiable belief system in this domain. In the remainder of this section we will first compare faculty views of teaching and learning to instructional paradigms found in the research literature. We will then discuss implications for further research needed to verify and extend our initial model. Finally, we will discuss possible implications for curriculum and professional development that might arise from this line of research.

\section{A. Comparison with three instructional paradigms}

Farnham-Diggory identifies three paradigms that underlie all instructional theory: ${ }^{16}$ behavior, development, and apprenticeship. Each is founded on assumptions about the difference between a novice and an expert and the key mechanism of transformation from novice to expert. These are briefly explained below so that they can be compared with the beliefs of the instructors in this study.

(1) Behavior: The difference between a novice and an expert is quantitative-experts simply know more than novices. Instruction involves an expert breaking down the knowledge or skills to be learned into a sequence of smaller steps. The role of the students is to master each step by practice and repetition. The role of the teacher is to present each step, provide opportunities for students to practice, and provide appropriate reinforcements to encourage success.

(2) Development: The difference between a novice and an expert is qualitative- experts have different cognitive structures than novices. Learners actively construct their mental models through a process of resolving the conflict between their existing ideas of the world and discrepant new insights. Instruction based on this theory involves probing students' existing models, then creating activities that (a) challenge their models, (b) help students build new models, and (c) help students apply their new models to novel contexts. The role of the students is to discover the discrepant events in carefully sequenced curricular material. The role of the teacher is to assure that students participate in activities that lead to the desired discrepant events, and appreciate the event as discrepant, and to help students build a new model that is consistent with their experiences.

(3) Apprenticeship: The difference between a novice and an expert is their culture of practice. The fundamental units of instruction are meaningful, "whole" activities (e.g., solving authentic problems), as opposed to decontextualized skill-building or concept-building activities. The role of the student is to engage in activities that simulate those of the field they are learning. During these activities, they interact with their peers and with their instructor to reflect on the connection between their existing experiences and ideas and the ideas and procedures that more closely characterize the field. The role of the teacher is to (a) model explicitly the intellectual skills and processes of the discipline, (b) coach 
students while they use the procedures of the discipline to engage in scaffolded, authentic activities, and (c) gradually decrease this support (scaffolding) until students are independent.

The belief system of the instructors in this study regarding the nature of expert knowledge and the nature of learning is most closely aligned with cognitive apprenticeship. On the other hand, their belief system regarding their role as a teacher was not congruent with any of the three instructional paradigms. This alignment is reflected in the following dimensions:

\section{Nature of expert knowledge}

Instructors perceive problem solving in physics as a central goal of the course. They believe the elements needed for effective problem solving are the characteristics of the culture of physics, "how a professional thinks about these sorts of things" [I6, 20]. They perceive expert knowledge as qualitatively different than that of the novice. They reject a view of expert problem solving as an accumulated knowledge built from an acquaintance with a large set of physics problems, although they recognize that this is the view of some of their students.

"I'm afraid we have cases of students who... go and look at the solutions and read them and say, ok now I've read, or sort of gone through solutions for 50 problems, I know the physics". [I4, 20]

In this sense, their vision of expert knowledge is similar to a cognitive apprenticeship paradigm, namely that experts differ from novices in their intellectual context. Their goals for student problem solving are consistent, to some extent, with expert problem solving reported in the literature. ${ }^{60,69-73}$ These goals include students learning to:

(1) use effective problem solving approaches that consist of an initial qualitative analysis of the problem, devising a plan, and evaluating the plan. Some believe this approach takes place in a linear process and others believe in an exploratory process that conforms more closely with the characterization of expert problem solving in the literature;

(2) demonstrate an understanding of physics concepts by their correct use in problem solving;

(3) deploy specific physics and mathematics techniques when appropriate;

(4) use self-evaluation both to guide the problem-solving process and facilitate learning physics through problem solving; and

(5) appreciate problem solving as an intellectual challenge.

Although the literature suggests that there are multiple stages that characterize the journey from novice to expert ${ }^{74,75}$ and recognizes the necessity of establishing intermediate goals for instructional purposes, these instructors had a dichotomist view regarding problem solving. They did not recognize any intermediate stages between expert and novice problem solvers that might help guide their instruction.

\section{Role of learner}

The instructors believe their students learn to solve problems by watching an expert performance embodied in their lectures and example problem solutions and by reflectively attempting to work problems. It is this reflectivity that allows students to use the teacher's modeling and other feedback to diagnose their own problem-solving deficiencies and remedy them. According to the instructors, the primary role of the learner is reflective: during the activity of problem solving the student examines and expands upon their own ideas and consciously generalizes and refines them. The instructors believed that this reflective approach was both a prerequisite to effectively learn in their course and a desired outcome of the course that was unattainable for most students. The instructors appear hostile to the behaviorist view of learning as a process of individually mastering small steps that are predetermined by an expert and putting those steps together in a predefined order.

\section{Role of teacher}

The instructors' belief system contained several conflicting ideas about their role as teachers. Because different ideas were activated in different contexts, the instructors were not usually aware of the conflicts. They had internal conflicts between their physicist values and their teacher values (valuing compact solutions vs well-communicated reasoning) and also within their teacher values (strict guidance vs extreme inquiry). Under the weight of perceived external constraints (workload, students' expectations, and limited professional knowledge), those physicist values that emphasized product over process tended to dominate teacher values that emphasized process.

The instructors' ideas about the role of the teacher appeared to be an extreme form of constructivism coupled with features of apprenticeship. In their view, the most important aspect of learning takes place while a student works a problem. While engaged in solving this problem a student constructs their knowledge. The guiding principle of their teaching seemed to be modeling their own problem solving as an example of expert problem solving without being explicit enough to limit students' freedom of thought or clash with their expectations. Coaching was valued, but no scaffolding should be used that constrains student actions and thus limits their creativity. A Socratic-like dialogue with students that supplies verbal scaffolding in office hours was not viewed as a limit on student creativity. Most coaching was viewed as giving feedback about student mistakes and allowing each student to find their own way to a correct path. Some instructors accepted, with reservations, the scaffolding of dividing problems into small, predefined subproblems, each of which focused on a single concept or skill that the instructor perceived led to a solution.

There appeared to be a mismatch between the instructors' view of student learning and their own actions in teaching. While the instructors believed that reflective practice is essential for student learning and that most students in their course were not reflective, they did not believe that they should design scaffolding to help students develop that reflectivity. They were content with giving general suggestions on how to approach learning and solve problems effectively. This belief that they should not directly influence student behavior occurred despite their very strong beliefs about the 
need for student behavior to change in this domain. The instructors were not satisfied with how "the typical student" engaged in learning activities. They pointed out student deficiencies similar to those reported in the educational literature. They believe that their students hold a naive view of physics problem solving as "matching problems with facts or equations and then substituting values" 76 and that students often believe that mathematical problem solving should be quick and straightforward. ${ }^{59}$ They also believe that students do not engage in the reflective learning activities ${ }^{60,76}$ and that the students' poor self-esteem can impede their ability to learn in the course. ${ }^{77}$

Despite the instructors' description of the typical student as not having the required learning skills to achieve the goals of their course, all of the instructors estimated that their students did learn between "some" and "a lot" in most categories that the instructors deemed to be appropriate knowledge by the end of the course. The only exceptions were categories that specifically involved reflection, such as students understanding the process of problem solving or the use of that understanding to evaluate their problem-solving process and results. That students would develop some ability to reflect on their problem solving was perceived as beyond the scope of an introductory physics course. No instructor indicated an awareness that this reflectivity, which at the end of the interview was judged to be too advanced for the course, was just the collection of thought processes that they espoused as a necessary condition for learning in the course.

\section{B. Implication for further research}

Based on our interviews of six professors from a single research university, we have constructed a model of the beliefs and values of physics faculty with respect to teaching problem solving within the context of introductory physics. This model is part of the characterization of the initial state of the instructor in a systems approach to changing instruction at universities and colleges. A knowledge of this initial state is required to design the scaffolded professional development that could result in the desired final state of the instructor, the productive adaptation of research-based curricular material and pedagogy.

This model allows the formulation of testable hypotheses that can and should be investigated by other means. Despite the safeguards built into this study, any interview technique has the possibility of contamination due to the interaction with the interviewer. Additional biases arise from the interpretation of the statements in the interview and their categorization imposed by the investigators. For these reasons it is important that independent investigators attempt to verify or falsify the results. These results should also be tested for their generality by similar interviews with a more diverse population of physics faculty from the different types of institutions that comprise the higher education system in the U.S. and other countries.

Because there is a close connection between the students in university introductory physics and high school physics, both in age of student and content of the course, we believe researchers should investigate the linkage between these two teaching contexts. Understanding the relationship between high school and college teaching is crucial for an effective education system because the high school teachers prepare the students who populate the university courses and high school teachers themselves are the direct product of the university. Of course, this type of study can also be used to investigate instructor beliefs about other parts of physics education such as establishing student knowledge about certain concepts. It can also be used to investigate instructors' belief structure when teaching other subjects.

The hypotheses, represented by the categories and links of the concepts maps presented in this paper, can be tested in detail and those results used to modify the model. The existence of a specific instructor belief and its relationships to their other beliefs about students, instructors, course content, external constraints, or the intellectual and cultural values of physics, represented by links on the concept maps, can be investigated by more directed interview techniques or in a statistical manner by the use of written questionnaires probing a limited domain of interest.

\section{Implication for curriculum and professional development}

It will take several years to achieve a detailed research program that goes from this initial model to a robust map representing the beliefs and values of a majority of physics professors about the teaching and learning of problem solving in the context of introductory physics. In the following, we use the initial model to formulate hypotheses to illustrate how such a map might be used by those attempting to change current pedagogy. We do not claim that this model has been tested and elaborated sufficiently to actually use in this manner.

\section{Identifying problems with professional development based on attacking transmissionist beliefs about teaching and learning}

Our model implies that, although many physics instructors present their courses in a manner in which their goal appears to be to transmit information to students, this is not the case. Indeed, their unstated "learning theory" could be characterized as extreme constructivist. Moreover, their beliefs about problem solving are very close to the accepted views about the nature of expert knowledge and its differences with novice knowledge. Their pedagogical style does not arise from a belief that students learn from clear explanations, a transmissionist learning theory. Instead it is the result of a more complex interplay among their beliefs about student learning, professional values, and perceived external constraints. This hypothesis implies that instructors do not need to be convinced that students must construct their own knowledge. Introducing them to this research is not likely to change their teaching because they already believe this is true.

\section{Designing new instructional materials}

Our initial model indicates that physics instructors have some dichotomous beliefs and many conflicting beliefs and values about the learning and teaching of problem solving. 
This result is supported by similar, more general studies with $\mathrm{K}-12$ science teachers (see Sec. II). This result also suggests that a tested and revised model will not help curriculum developers design materials that would be accepted and used by physics faculty without additional professional development.

For example, some of the faculty interviewed stated the need for example problem solutions that make explicit the expert thought processes in problem solving. They believed that they had neither the time nor the professional knowledge to construct such materials. This would seem to imply that curricular materials designed to improve student problem solving $23,25,26,76$ should supply a complete set of such solutions for the course. However, the explicitness of such solutions would violate the value of not constraining student creativity by giving an explicit trail of reasoning. It would also violate the value of concise communication by explicitly describing reasoning processes that are typically implicit for an expert. Finally it would violate the value of not undermining student morale by making problem solving look too complicated. Thus one should not expect the availability of such materials to lead to their acceptance or use.

Another example is providing activities in which it is necessary for students to use organized and well-communicated problem solving to accomplish a task. ${ }^{78}$ Such a task might be working in small collaborative groups to solve a realistic, complex problem. This task requires coaching and other scaffolding for most students to be successful. While instructors believe that reflective practice solving problems is essential for learning, they also believe that no scaffolding should be used that constrains student actions and limits their creativity. Instructors also do not recognize any intermediate stages between novice and expert problem solving that might help guide their instruction. Additional professional development would probably be required to strengthen an instructor's belief in the need for scaffolding to help students become more expert-like problem solvers.

\section{Designing short, one-time professional development interventions}

A knowledge of instructors' beliefs and values can allow curriculum developers to determine the alignment of their materials with instructors. If the materials are reasonably well aligned and do not conflict with any deeply held beliefs or values, those instructors are potential adopters. A conventional dissemination strategy of short professional development workshops, designed to reinforce faculty conceptions that align with the proposed materials while weakening undesirable beliefs by pointing out conceptual conflicts, could be effective.

For example, in disseminating curricular materials in which problem solving serves as a primary mode of learning introductory physics ${ }^{6-11}$ one might initially think that it would be most important to focus on expert-novice differences in problem solving. An introduction to the results of this research ${ }^{60}$ might be a useful introduction and prove reaffirming for faculty. However, it is already aligned with their beliefs and thus is not likely to change their teaching. With this knowledge, the professional development would need to go further, perhaps focusing effort on introducing the concept of scaffolding, as their beliefs have features of cognitive apprenticeship without the crucial idea of the use of scaffolding. It is possible that exposure to models of cognitive apprenticeship instruction with an emphasis on the building and eliminating of scaffolding would be close enough to the instructors' beliefs to be beneficial.

Short-term professional development could also explicitly focus on exposing major inconsistencies in instructors' complex belief structure. This could be accomplished by focusing on instructional materials that are known to cause conflicts. For example, we found that instructors have conflicts about the role of context in problems and the consequences of subdividing problems into parts. It might be beneficial for an instructor to articulate their conflict while clarifying both their values and perceived constraints that shape their instructional practice. At this point, instructors might be receptive to instructional strategies which resolve the conflicts using scaffolding techniques.

Professional development could also focus instructors on other issues about which they are likely to have internal inconsistencies. For example, their perception of student learning matches their perception of useful instruction only if their students are reflective learners, which they recognize is not the case. One could build upon the similarity of their beliefs regarding the nature of problem solving and learning to research results by assisting them to articulate their goals and their expectations of students entering their class. At the same time, they could examine the characteristics of their students so that they might recognize the gap between their requirements for effective student learning and their actual students' characteristics. Once exposed, these inconsistencies may provide instructors with motivation to engage in longterm professional development that allows them to become familiar with techniques that resolve this conflict.

\section{Designing long-term professional development}

If new curricular materials violate key instructor beliefs or values, one needs to design a thorough professional development to accompany and support a long-term process of a fundamental cognitive change. This would require an intellectual environment that does not currently exist at most universities and colleges. The time required for such professional development would need to be made available to instructors at the expense of one or more of their other duties. Research on in-service teacher education points out the characteristics of professional development needed to achieve such changes and encourage teachers to face the risks and cope with the difficulties entailed in such a transformation. ${ }^{79-81}$ As in any human change of deep-rooted beliefs, the instructors will need to take an active role by consciously reflecting on their beliefs and practices while tailoring the innovations to their specific context. ${ }^{82-84}$ Such changes would need a model of professional development that is more extensive than a several hour or even several day workshop. This model would probably need to be implemented while the instructors are in the process of teaching a course and involve the modeling, coaching, and fading aspects of cognitive apprenticeship. Unless this time of exten- 
sive and long-term professional development is envisioned when the curricular material or pedagogy was designed, the most effective action for change would probably be to develop materials that avoid this intellectual confrontation.

\section{ACKNOWLEDGMENTS}

This study was partially funded by the National Science
Foundation Grant No. DUE-9972470 and the University of Minnesota. Additional assistance was provided by the Weizmann Institute. We would like to thank the faculty and graduate students of the University of Minnesota who participated in this study and the preliminary studies that led to the development of the interview procedure.
*Previously at School of Physics and Astronomy, University of Minnesota, Minneapolis, MN 55455, USA.

${ }^{\dagger}$ Present address: Department of Physics, Colorado School of Mines, Golden, CO, 80401, USA.

${ }^{1}$ K. Samuelowicz and J. D. Bain, Conceptions of teaching held by academic teachers, J. Higher Educ. 24, 93 (1992).

${ }^{2}$ M. Prosser and K. Trigwell, Understanding Learning and Teaching: The Experience in Higher Education (St. Edmundsbury Press, Great Britain, 1999).

${ }^{3}$ C. Brass, R. F. Gunstone, and P. Fensham, Quality Learning of Physics: Conceptions Held by High School and University Teachers, Res. Sci. Educ. 33, 245 (2003).

${ }^{4} \mathrm{C}$. Henderson and M. Dancy, in Proceedings (peer reviewed) of the 2004 AAPT Physics Education Research Conference, edited by S. Franklin, J. Marx, and P. Heron (American Institute of Physics, Melville, NY, 2005).

${ }^{5}$ A. G. Thompson, in Handbook of Research on Mathematics Teaching and Learning, edited by D. A. Grouws (MacMillan, New York, 1992), p. 127.

${ }^{6}$ J. P. Mestre, R. J. Dufrense, W. J. Gerace et al., Promoting skilled problem-solving behavior among beginning physics students, J. Res. Sci. Teach. 30, 303 (1993).

${ }^{7}$ A. Van Heuvelen, Learning to think like a physicist: A review of research based instructional strategies, Am. J. Phys. 59, 891 (1991).

${ }^{8} \mathrm{P}$. Heller and M. Hollabaugh, Teaching problem solving through cooperative grouping. Part 2: Designing problems and structuring groups, Am. J. Phys. 60, 637 (1992).

${ }^{9}$ P. Heller, R. Keith, and S. Anderson, Teaching problem solving through cooperative grouping. Part 1: Groups versus individual problem solving, Am. J. Phys. 60, 627 (1992).

${ }^{10}$ W. J. Leonard, R. J. Dufrense, and J. P. Mestre, Using qualitative problem solving strategies to highlight the role of conceptual knowledge in solving problems, Am. J. Phys. 64, 1495 (1996).

${ }^{11}$ F. Reif, Millikan Lecture 1994: Understanding and teaching important scientific thought processes, Am. J. Phys. 63, 17 (1995).

${ }^{12}$ C. Bereiter and M. Scardamalie, in Handbook of Research on Curriculum, edited by P. W. Jackson (MacMillan, New York, 1992), p. 517.

${ }^{13}$ J. S. Brown, A. Collins, and S. Duguid, Situated Cognition and the Culture of Learning, Educ. Res. 18, 32 (1989).

${ }^{14}$ A. Collins, J. S. Brown, and A. Holum, Cognitive apprenticeship: Making thinking visible, Am. J. Educ., 6, 38 (1991).

${ }^{15}$ A. Collins, J. S. Brown, and S. E. Newman, Knowing, Learning, and Instruction: Essays in Honor of Robert Glaser, edited by L. B. Resnick (Erlbaum, Hillsdale, NJ, 1989).

${ }^{16} \mathrm{~S}$. Farnham-Diggory, Paradigms of Knowledge and Instruction, Rev. Educ. Res. 64, 463 (1994).
${ }^{17}$ K. Cummings, J. Marx, R. Thornton, and D. Kuhl, Evaluating innovation in studio physics, Am. J. Phys. 67, S38 (1999).

${ }^{18}$ M. Prosser, K. Trigwell, and P. Taylor, A phenomenographic study of academics' conceptions of science learning and teaching, Learn. Instr. 4, 217 (1994).

${ }^{19}$ J. B. Biggs, Approaches to enhancement of tertiary teaching, Higher Educ. Res. Dev. 8, 7 (1989).

${ }^{20}$ E. Martin and M. Balla, Conceptions of teaching and implications for learning, Res. Higher Educ. 13, 298 (1991).

${ }^{21} \mathrm{~K}$. Trigwell, M. Prosser, F. Marton et al., in Teacher Thinking, Beliefs and Knowledge in Higher Education, edited by $\mathrm{N}$. Hativa and P. Goodyear (Kluwer, Dordrecht, The Netherlands, 2002), p. 241.

22 J. G. Donald, Professors' and Students' Conceptualizations of the Learning Task in Introductory Physics Courses, J. Res. Sci. Teach. 30, 905 (1993).

${ }^{23}$ J. H. Van Driel, N. Verloop, H. I. Van Werven et al., Teachers' craft knowledge and curriculum innovation in higher engineering education, J. Higher Educ. 34, 105 (1997).

${ }^{24} \mathrm{~J}$. Calderhead, in Handbook of Educational Psychology, edited by D. C. Berliner and R. C. Calfee (Prentice-Hall, New York, 1996), p. 709.

${ }^{25}$ A. Lumpe, C. Czerniak, and J. Haney, Science teacher beliefs and intentions regarding the use of cooperative learning, Sch. Sci. Math. 98, 123 (1998).

${ }^{26} \mathrm{E}$. Yerushalmi and B. Eylon, in Proceedings of the International GIREP Conference on Physics Teacher Education beyond 2000 (GIREP, Barcelona, Spain, 2001).

${ }^{27}$ I. Huibregtse, F. Korthagen, and T. Wubbels, Physics teachers' conceptions of learning, teaching and professional development, Int. J. Sci. Educ. 16, 539 (1994).

${ }^{28}$ A. H. Schoenfeld, Towards a theory of teaching-in-context, Issues Educ. Res. 4, 1 (1998).

${ }^{29}$ D. C. Berliner, in Exploring Teachers' Thinking, edited by J. Calderhead (Cassell Educational Limited, London, Great Britain, 1987), p. 60.

${ }^{30}$ D. C. Berliner, in New Directions for Teacher Assessment (Proceedings of the 1988 ETS Invitational Conference), edited by J. Pfleiderer (Educational Testing Service, Princeton, NJ, 1988), p. 39.

${ }^{31} \mathrm{~K}$. Carter and W. Doyle, Teachers' knowledge structures and comprehension processes, J. Higher Educ. 59, 186 (1987).

${ }^{32}$ M. J. Dunkin and R. P. Precians, Award-winning university teachers' concepts of teaching, J. Higher Educ. 24, 483 (1992).

${ }^{33} \mathrm{O}$. Kwo, in Teachers' Minds and Actions: Research on Teachers' Thinking and Practice, edited by I. Carlgren, G. Handal, and S. Vaage (Falmer Press, London, 1994), p. 215.

${ }^{34}$ J. Mitchell and P. Marland, Research on teacher thinking: The 
next phase, Teach. Teach. Educ. 5, 115 (1989).

35 J. Piaget, The Child's Conception of the World (Harcourt, Brace, New York, 1929).

${ }^{36}$ J. Piaget, The Child's Conception of Movement and Speed (Routledge, London, 1970).

${ }^{37}$ R. Driver, E. Guense, and A. Tiberghien, Children's Ideas in Science (Open University Press, Buckingham, UK, 1985).

${ }^{38}$ R. Driver and J. Easley, Pupils and paradigms: a review of the literature related to concept development in adolescent science students, Stud. Sci. Educ. 5, 61 (1978).

${ }^{39}$ J. H. Wandersee, J. J. Mintzes, and J. D. Novak, in Handbook of Research on Science Teaching and Learning, edited by D. Gabel (MacMillan, New York, 1994), p. 177.

${ }^{40} \mathrm{~L}$. McDermott, Research on conceptual understanding in mechanics, Phys. Today 37, 24 (1987).

${ }^{41} \mathrm{~S}$. Strauss, in Understanding and Teaching the Intuitive Mind, edited by B. Torff and R. J. Sternberg (Erlbaum, Mahwah, NJ, 2001), p. 217.

${ }^{42}$ National Research Council, How People Learn: Brain, Mind, Experience, and School (National Academy Press, Washington, DC, 1999).

${ }^{43}$ O. Lantz and H. Katz, Chemistry teachers' functional paradigms, Sci. Educ. 71117 (1987).

${ }^{44} \mathrm{~J}$. Nespor, The role of beliefs in the practice of teaching, J. Curric. Stud. 19, 317 (1987)

${ }^{45}$ S. M. Wilson, L. S. Shulman, and A. E. Richert, in Exploring Teachers' Thinking, edited by J. Calderhead (Cassell Educational Limited, London, 1987).

${ }^{46}$ M. F. Pajares, Teachers' beliefs and education research: Cleaning up a messy Construct, Rev. Educ. Res. 63, 307 (1992).

${ }^{47} \mathrm{~J}$. Hutchinson and M. Huberman, Knowledge dissemination and use in science and mathematics education: literature review (National Science Foundation, Arlington, VA, 1993).

${ }^{48}$ R. Yerrick, H. Parke, and J. Nugent, Struggling to promote deeply rooted change: The "Filtering effect" Of teachers' beliefs on understanding transformational views of teaching science, Int. J. Sci. Educ. 81, 137 (1997).

${ }^{49}$ J. W. Stigler and J. Hiebert, The Teaching Gap: Best Ideas from the World's Teachers for Improving Education in the Classroom (The Free Press, New York, 1999).

${ }^{50}$ D. Winter, P. Lemons, J. Bookman, and W. Hoese, Novice instructors and student-centered instruction: Identifying and addressing obstacles to learning in the college science laboratory, J. Scholarship Teach. Learn. 2, 15 (2001).

${ }^{51}$ M. I. Honig and T. C. Hatch, Crafting coherence: How schools strategically manage multiple, external demands, Educ. Res. 33, 16 (2004).

${ }^{52}$ J. P. Spillane, Standards Deviation: How Schools Misunderstand Educational Policy (Harvard University Press, Cambridge, MA, 2004).

${ }^{53}$ F. Reif, Phys. Today 39, 48 (1986).

${ }^{54}$ J. W. Creswell, Qualitative Inquiry and Research Design: Choosing among Five Traditions (Sage, Thousand Oaks, CA, 1998).

${ }^{55}$ R. J. Shavelson and P. Stern, Research on teachers' pedagogical thoughts, judgments, decisions, and behavior, Rev. Educ. Res. 51, 455 (1981).

${ }^{56}$ A. L. Strauss, Qualitative Analysis for Social Scientists (Cambridge University Press, Cambridge, 1987).

${ }^{57}$ A. L. Strauss and J. Corbin, Basics of Qualitative Research: Grounded Theory Procedures and Techniques (Sage, Newbury
Park, CA, 1990).

${ }^{58}$ C. Henderson, E. Yerushalmi, K. Heller, P. Heller, and V. Kuo, Phys. Rev. ST Phys. Educ. Res. 3, 020110 (2007).

${ }^{59}$ A. Schoenfeld, Mathematical Problem Solving (Academic Press, New York, 1985).

${ }^{60}$ D. Maloney, in Handbook of Research on Science Teaching and Learning, edited by D. Gabel (MacMillan, New York, 1994).

${ }^{61} \mathrm{P}$. Heller, T. Foster, and K. Heller, in The Changing Role of Physics Departments in Modern Universities: Proceedings of the International Conference on Undergraduate Physics Education, edited by E. F. Redish and J. S. Rigden (American Institute of Physics, Woodbury, NY, 1996), p. 913.

${ }^{62}$ F. Lawrenz, P. Heller, R. Keith, and K. Heller, Training the teaching assistant: Matching the ta strengths and capabilities to meet specific program goals, J. Coll. Sci. Teach. 22, 106 (1992).

${ }^{63} \mathrm{~T}$. Foster, in Curriculum and Instruction (University of Minnesota, Minneapolis, MN, 2000).

${ }^{64} \mathrm{R}$. H. Hycner, Some guidelines for the phenomenological analysis of interview data, Hum. Stud. 8, 279 (1985).

${ }^{65}$ J. D. Novak and D. B. Gowin, Learning How to Learn (Cambridge University Press, New York, 1984).

${ }^{66}$ C. Henderson, E. Yerushalmi, V. Kuo, P. Heller, and K. Heller, Grading Student Problem Solutions: The Challenge of Sending a Consistent Message, Am. J. Phys. 72, 164 (2004).

${ }^{67}$ M. Dancy and C. Henderson, in Proceedings of the 2004 AAPT Physics Education Research Conference, edited by S. Franklin, J. Marx, and P. Heron (American Institute of Physics, Melville, NY, 2005).

${ }^{68}$ J. A. Michael and H. I. Modell, Active Learning in Secondary and College Science Classrooms (Lawrence Erlbaum, Mahwah, NJ, 2003).

${ }^{69}$ J. D. Bransford et al., in Cognition, Education and Multimedia, edited by D. Nix and R. Sprio (Erlbaum Associates, Hillsdale, NJ, 1990).

${ }^{70}$ J. D. Bransford and B. S. Stein, The Ideal Problem Solver, 2nd ed. (Freeman, New York, 1993).

${ }^{71}$ M. Cole, in Vygotsky and Education: Instructional Implications and Applications of Sociohistorical Psychology, edited by L. Moll (Cambridge University Press, Cambridge, UK, 1990), pp 89-110.

${ }^{72}$ P. Cobb and E. Yackel, Constructivist, emergent, and sociocultural perspectives in the context of development research, Educ. Psychol. 31, 175 (1996).

${ }^{73}$ G. Polya, How to Solve It (Princeton University Press, Princeton, 1957).

${ }^{74}$ H. L. Dreyfus and S. E. Dreyfus, Five Steps from Novice to Expert (Free Press, New York, 1986).

${ }^{75}$ H. L. Dreyfus and S. E. Dreyfus, in Advances in Cognitive Science, edited by N. E. Sharkey (Ellis Horwood Limited, West Sussex, England, 1986).

${ }^{76}$ E. F. Redish, J. M. Saul, and R. N. Steinberg, Student expectations in introductory physics, Am. J. Phys. 66, 212 (1998).

${ }^{77}$ P. R. Pintrich and E. V. D. Groot, Motivational and self-regulated learning components of classroom academic performance, J. Educ. Psychol. 82, 33 (1990).

${ }^{78}$ E. Yerushalmi and E. Magen, Same old problem, new name? Alerting students to the nature of the problem-solving process, Phys. Educ. 41, 161 (2006). 
${ }^{79}$ R. T. Putnam and H. Borko, What do new views of knowledge and thinking have to say about research on teacher learning?, Educ. Res. 29, 4 (2000).

${ }^{80}$ S. Loucks-Horsley, P. Hewson, N. Love et al., Designing Professional Development for Teachers of Science and Mathematics (Corwin Press, Thousand Oaks, CA, 1998).

${ }^{81}$ National Research Council, The National Science Education Standards (The National Academies Press, Washington, DC,
1996).

${ }^{82}$ L. Shulman, Those who understand: Knowledge growth in teaching, Educ. Res. 15, 4 (1986).

${ }^{83}$ R. Sternberg and J. Horvath, A prototype view of expert teaching, Educ. Res. 24, 9 (1995).

${ }^{84} \mathrm{~W}$. Lauden, in Understanding Teacher Development, edited by A. Hargreaves and M. G. Fullan (Teacher College Press, New York, 1992). 